\title{
Long-Term Intruding Effects of Acid Rain on Engineering Properties of Primary and Secondary Kaolinite Clays
}

\author{
Zeinab Bakhshipour ${ }^{1}$ - Afshin Asadi ${ }^{2}$ Bujang B. K. Huat ${ }^{1}$ - A. Sridharan ${ }^{3,4}$
}

Received: 26 January 2016/Accepted: 1 June 2016/Published online: 8 July 2016

(C) Springer International Publishing Switzerland 2016

\begin{abstract}
In this study, the effects of simulated acid rain (SAR) on the engineering properties of primary and secondary kaolinite clays (PK and SK) were investigated. Tests of consistency limit, compressive strength, compressibility, hydraulic conductivity, and compaction characteristics were conducted to investigate the changes in the physico-chemical and engineering properties of PK and SK clays after being exposed to SAR at different $\mathrm{pH}$ levels of $2,3,4,5$, and 5.6 and at different fluxes of SAR equivalent to precipitation for $1,5,10$, and 20 years. In addition, scanning electron microscope (SEM) and energy dispersive X-ray spectroscopy (EDX), zeta potential and atomic adsorption spectroscopy (AAS) studies were conducted to identify the underlying mechanisms involved. The results revealed that for both PK and SK, the low $\mathrm{pH}$ value of SAR and higher flux of SAR resulted in a reduction in soil strength, maximum dry density, and increased
\end{abstract}

Zeinab Bakhshipour

bakhshipour.azadeh@gmail.com

Afshin Asadi

afshin.xxxdi@gmail.com

Bujang B. K. Huat

bujang@upm.my

A. Sridharan

sridharanasuei@yahoo.com

1 Department of Civil Engineering, Faculty of Engineering, Universiti Putra Malaysia, 43400 Serdang, Selangor, Malaysia

2 Housing Research Centre (HRC), Department of Civil Engineering, Faculty of Engineering, Universiti Putra Malaysia, 43400 Serdang, Selangor, Malaysia

3 Indian Institute of Science, Bangalore, India

4 Indian National Science Academy, New Delhi, India compressibility, hydraulic conductivity, liquid limit, and optimum moisture contents. The AAS tests confirmed that reduction of more traced elements in PK and SK specimens when they were infiltrated by the SAR. Also, the formation of relatively a weak structure was observed through the SEM tests. The sensitivity of the PK specimen was higher than that of the SK specimen for SAR intrusion.

Keywords Acid rain - Kaolinite clay · Atterberg limits · Consolidation · Compressive strength · Hydraulic conductivity $\cdot$ Compaction characteristics

\section{Introduction}

Acid rain is a secondary pollutant produced when acidic gases dissolve in water. Soils are polluted due to acid rain. This may change the chemistry within the soil environment. Sulfur dioxide $\left(\mathrm{SO}_{2}\right)$ and nitrogen oxides $\left(\mathrm{NO}_{\mathrm{x}}\right)$ are the major sources of acid rain [1-5]. These oxides react in rainwater to produce stronger acids and lower the $\mathrm{pH}$ to 4.5 or even 3.0. The engineering properties of soils are significantly influenced by the chemical properties of the medium, termed as "chemical-mechanical coupling" [6]. Many studies have focused on the effects of acid rain on the engineering properties of different soils [6-14]. From the literature, it can be seen that the following chemical and physical processes may describe the effect of acid rain on soil [7, 12]: (I) dissolution and leaching of cations or anions from soil based on their solubility at different $\mathrm{pH}$ values; (II) changes in surface electrical properties of the colloidal fraction of soil; (III) absorption of anions in acid rain such as $\mathrm{SO}_{4}^{2-}, \mathrm{NO}_{3}^{-}$, and $\mathrm{CO}_{3}^{2-}$ in the soil environment; and (IV) changes in diffuse double layer of clay fraction due to ion exchange and 
Fig. 1 Location of PK and SK soil samples a Primary kaolinite, b Secondary kaolinite

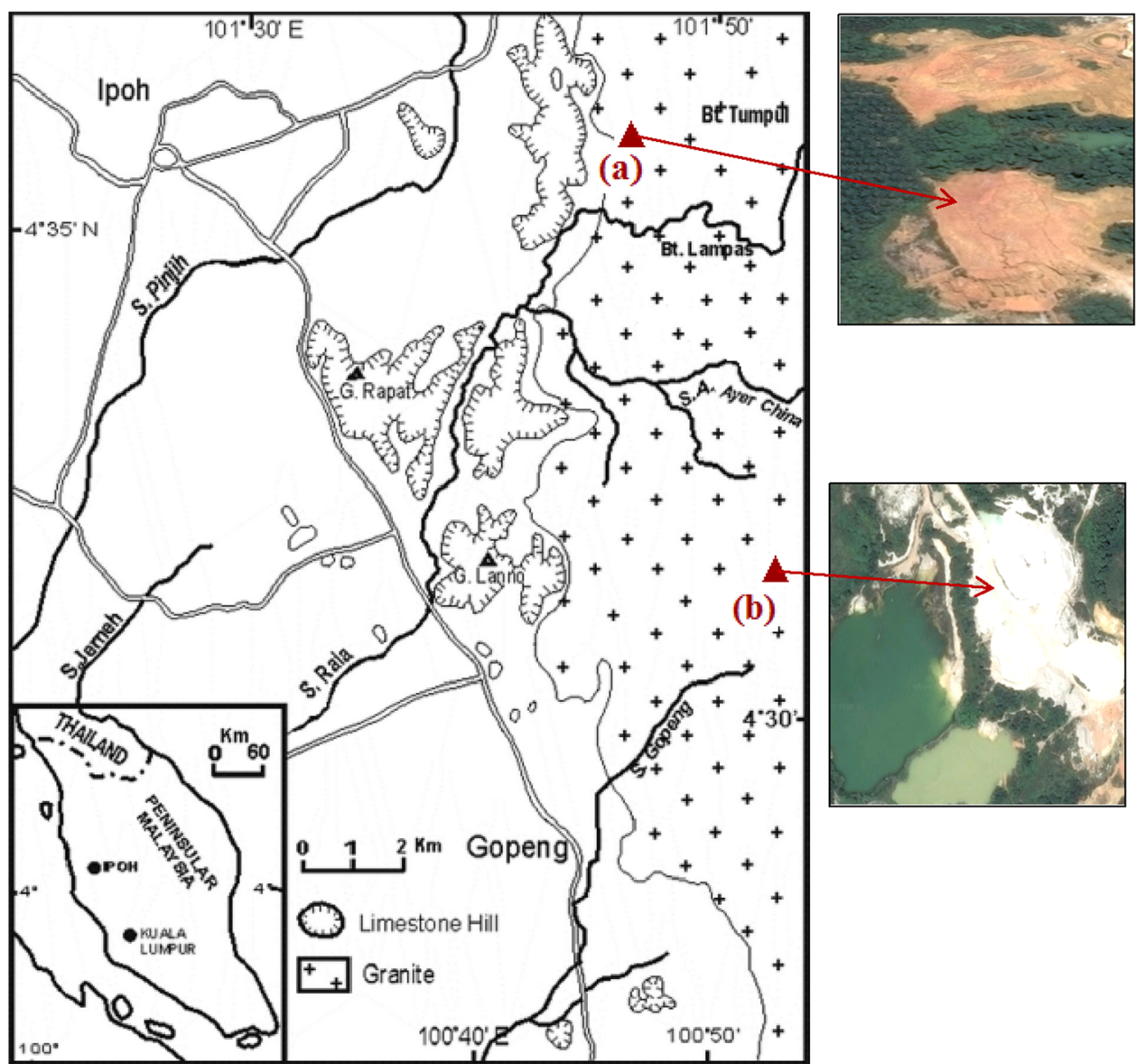

consequent changes in the van der Waals forces acting between the clay particles, which may result in a change in the engineering properties of soil affected by acid rain.

The aforementioned studies have shown that the effects of acid rain on the physico-chemical and engineering properties of soil could be different due to the different properties of the host soil and chemical properties of the pore fluid. Therefore, further studies are needed to elaborate the engineering properties of soil at acidic environmental conditions. Until the end of the 1970s, the problem of acid rain was only confined to European and North American countries. However, increased urbanisation and industrialisation in tropical countries such as Malaysia [15] have provided a basis for the occurrence of acid rain. Malaysia is one of the tropical areas that are beginning to experience the effects of acid rain. In Malaysia, from 1985 to 1992 , the mean $\mathrm{pH}$ values ranged from 5.0 to 5.7 in the sites not close to industrial areas, and from 4.3 to 5.0 for those near to industrial and densely populated areas [15].

It has long been recognised that in almost all soils of tropical climate areas such as Malaysia, kaolinite clay is one of the predominant clay minerals. Kaolinite clay is a 1:1 alumina silicate mineral composed of one octahedral sheet stacked above one tetrahedral sheet [16]. The two crystal units comprising one kaolinite clay particle are held together by hydrogen bonds, and the space between the structural layers, therefore, has a fixed dimension [17, 18]. Kaolinite clay with the formula of $\mathrm{Al}_{2} \mathrm{Si}_{2} \mathrm{O}_{5}(\mathrm{OH})_{4}$ is produced by weathering and typically has low cation exchange capacity (i.e. $2-15 \mathrm{meq} / 100 \mathrm{~g}$ ) [16]. Isomorphs substitution within the kaolinite clay crystal is limited, contributing to the low permanent charge. However, kaolinite clay may develop variable or $\mathrm{pH}$-dependent negative charge because of the dissociation of protons for exposed $\mathrm{OH}^{-}$groups $[17,18]$. The surface charge of kaolin in aqueous solutions is always negative, arising in general, directly from $\mathrm{Al}^{3+}$ substitution for $\mathrm{Si}^{4+}$ in the tetrahedral sheet of the mineral [19]. Kaolinite clay is divided into two broad categories: primary and secondary [16]. Primary kaolinite clay or residual kaolin originates from in situ alteration of rocks by hot fluids, which percolate mainly in pegmatite. Primary kaolinite clay is considered not to have been altered chemically since its deposition and crystallisation as a result of large-scale geological processes [20]. As most primary minerals are formed by tectonic activities, they are inherently unstable in soils and will dissolve [16]. In addition, primary kaolinite clay contains significant amounts of mica, K-feldspar and quartz [21]. 
Fig. 2 Particle size distribution of PK and SK samples

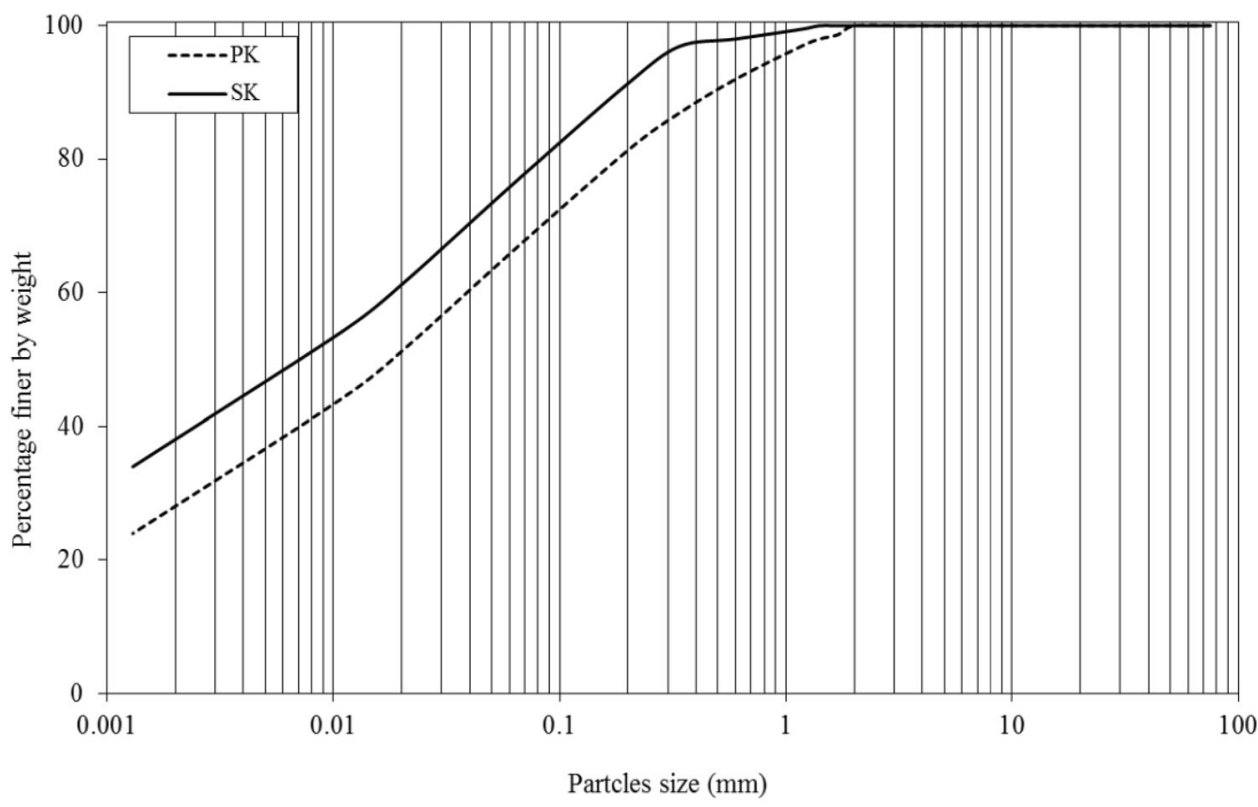

Table 1 Physical and chemical properties of PK and SK samples

\begin{tabular}{|c|c|c|}
\hline & PK (primary kaolinite) & SK (secondary kaolinite) \\
\hline \multicolumn{3}{|l|}{ Physical properties } \\
\hline Liquid Limit (LL) (\%) & 70 & 44 \\
\hline Plastic Limit (PL) (\%) & 40 & 41 \\
\hline Shrinkage Limit (SL) (\%) & 8 & 4 \\
\hline Plasticity Index (PI) (\%) & 30 & 14 \\
\hline Free Swell Index $(\%)$ & 33 & 36 \\
\hline Natural water content (W) $(\%)$ & 42.32 & 48.81 \\
\hline Specific Gravity $\left(\mathrm{G}_{\mathrm{S}}\right)$ & 2.53 & 2.50 \\
\hline Porosity (n) (\%) & 53.45 & 57.61 \\
\hline $\operatorname{MDD}(\gamma \mathrm{d})\left(\mathrm{Mg} / \mathrm{m}^{3}\right)$ & 1.12 & 1.04 \\
\hline $\mathrm{OMC}(\%)$ & 32 & 36 \\
\hline Unified Classification of soil & $\mathrm{CH}$ (fat clay) clay of high plasticity & CL clay of low plasticity \\
\hline \multicolumn{3}{|l|}{ Chemical properties } \\
\hline $\mathrm{XRF}$ & - & - \\
\hline $\mathrm{Fe}_{2} \mathrm{O}_{3}(\%)$ & 25.98 & 3.92 \\
\hline $\mathrm{SiO}_{2}(\%)$ & 42.01 & 56.38 \\
\hline $\mathrm{Al}_{2} \mathrm{O}_{3}(\%)$ & 23.92 & 27.27 \\
\hline $\mathrm{K}_{2} \mathrm{O}(\%)$ & 5.20 & 8.33 \\
\hline $\mathrm{pH}$ & 4.31 & 4.27 \\
\hline Cation exchange capacity (meq/100 g) & 10.21 & 8.93 \\
\hline
\end{tabular}

However, secondary minerals form from the decomposition and restructuring of primary minerals or from precipitation reactions involving chemical constituents of primary kaolinite clay released during dissolution [20, 22]. Secondary kaolinite clays are generally characterised by smaller particle size, because the particle size of primary kaolinite clay decreases during weathering and release of soluble materials [22, 23]. Most secondary kaolinite clays in soils are phyllosilicates: silicate-based minerals having sheets of silicate anions linked to sheets or cations (usually Al) to form a layer [24]. Therefore, secondary kaolinite clay has a more stable structure than 
Fig. 3 XRD analysis of original PK and SK soils (k) kaolinite, (q) quartz, (g) goethite, (h) hematite, (kfeldspar) kaolinite-feldspar, (s) smectite, (I) Illite, (ca) calcium

Fig. 4 Exposure setup a Schematic exposure setup A: SAR tank, B: top cap tank, C: filter paper, D: specimen, E: membrane, F: outflow water, b Exposure setup in laboratory

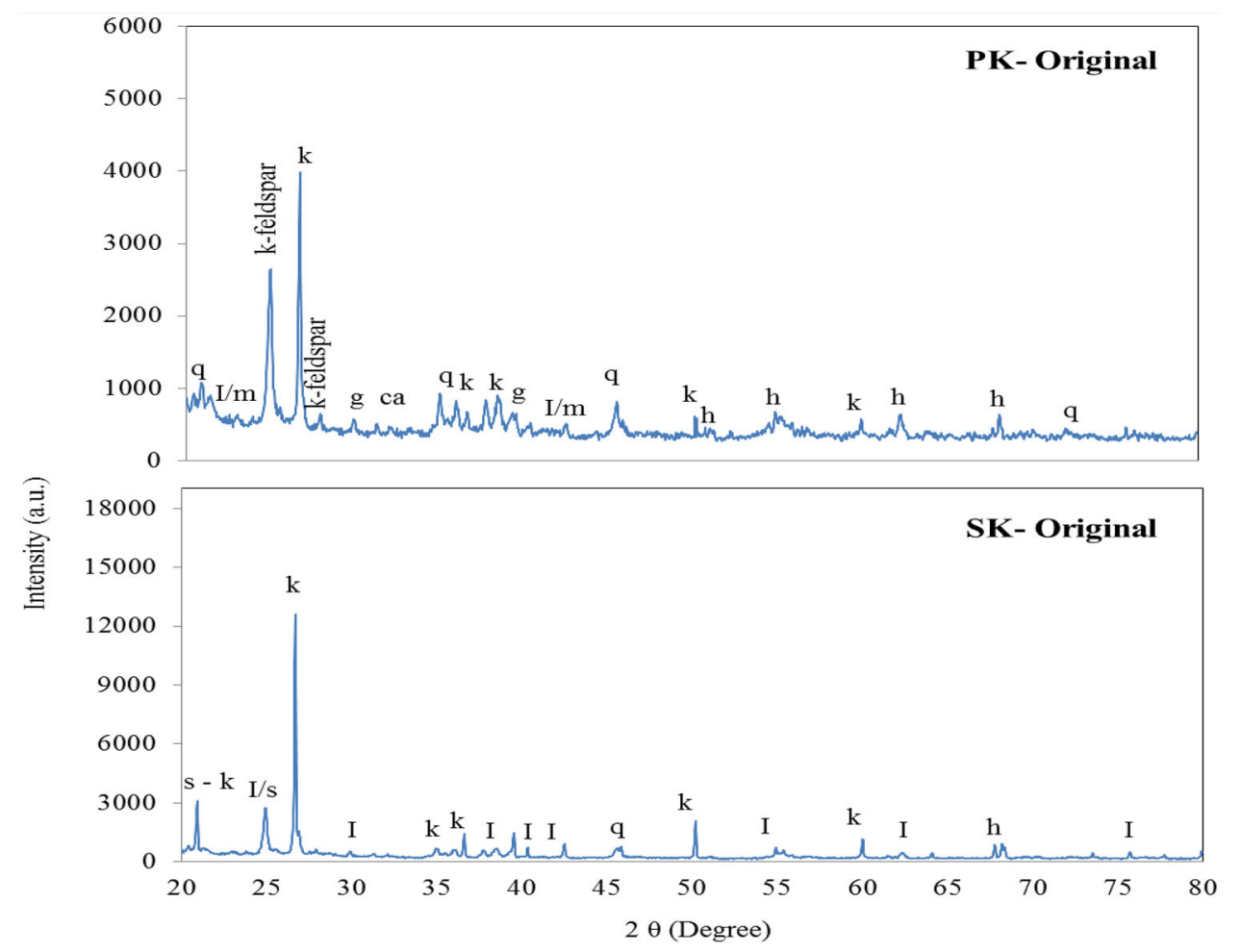

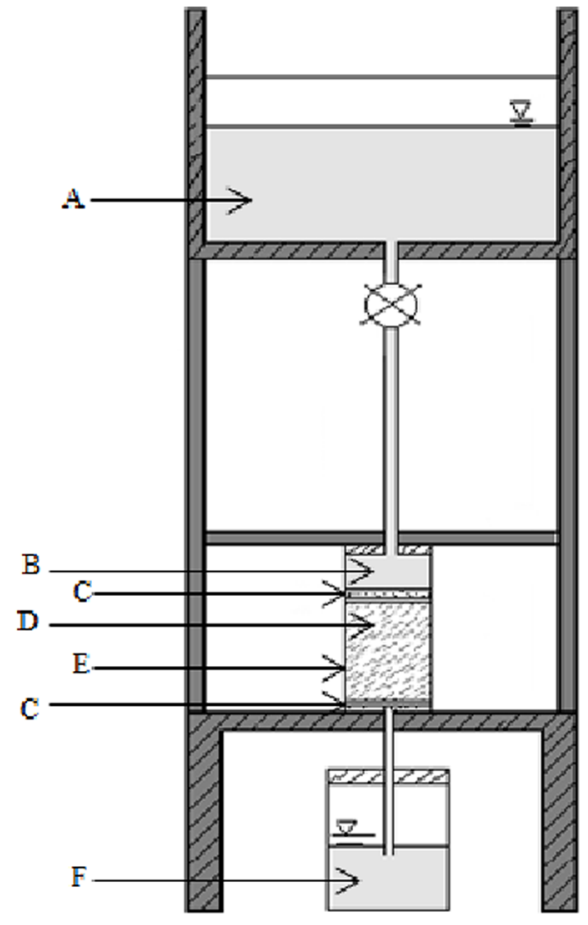

(a)

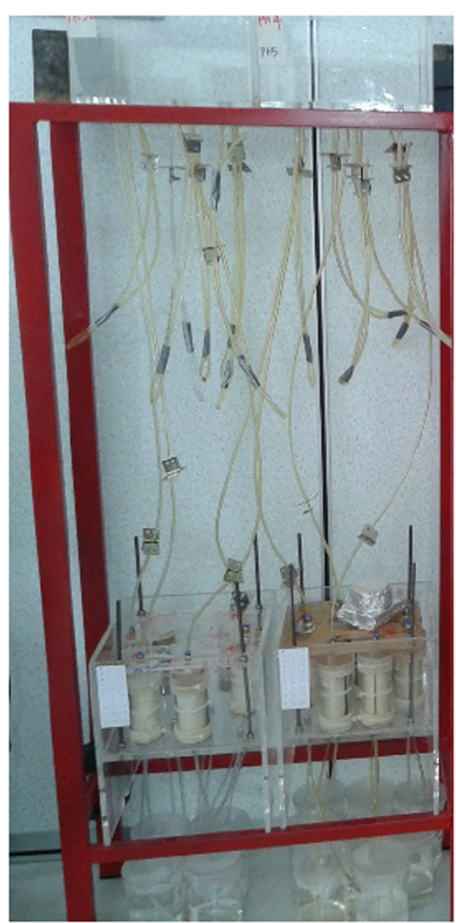

(b) that of primary kaolinite clay. Also, secondary kaolinite clay contains significant amounts of illite, vermiculite, and smectite [16].
Most of the soil types in Malaysia contain kaolinite clay as a clay mineral [25]. The climate conditions in Malaysia are characterised by high humidity and particularly 

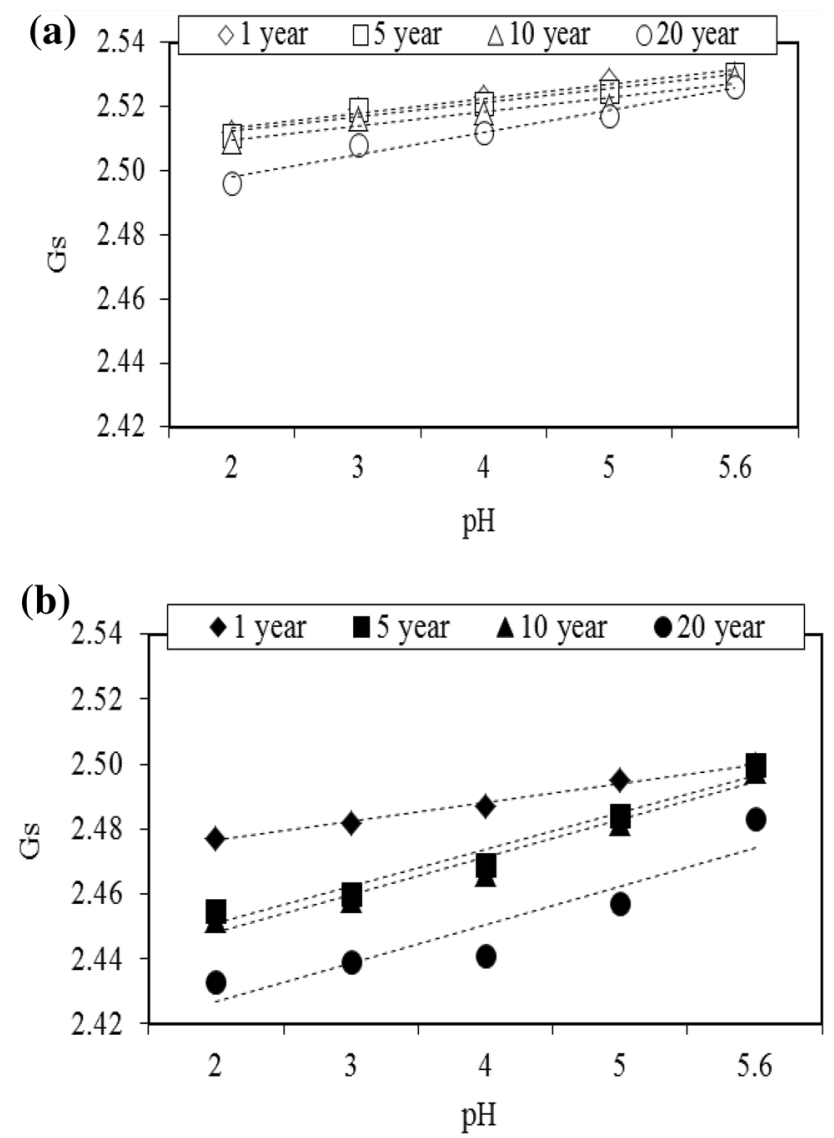

Fig. 5 Specific gravity of soils with respect to $\mathrm{pH}$ in flux of SAR 1 year to 20 years a PK sample, b SK sample

abundant acidic rainfall. Therefore, the effect of acid rain on the physico-chemical and engineering behavior of kaolinite clay is a good context for this study. This study aims to investigate the mechanical effects of simulated acid rain with $\mathrm{pH}$ values of $2,3,4,5$, and 5.6 on two types of kaolinite clay, including primary and secondary.

\section{Materials and Methods}

\section{Soil Properties}

Two types of kaolinite clay with different plasticity characteristics were selected. Primary kaolinite (PK) and secondary kaolinite $(\mathrm{SK})$ were obtained from Ipoh $\left(435^{\prime} \mathrm{N}\right.$ $\left.101^{\circ} 6^{\prime} \mathrm{E}\right)$ and Bedro $\left(4^{\circ} 32^{\prime} \mathrm{N} 101^{\circ} 54^{\prime} \mathrm{E}\right)$ respectively, as shown in Fig. 1. PK and SK were prepared by passing the original kaolinite clay through a $425 \mu \mathrm{m}$ sieve.

Figure 2 shows the particle size distribution of the specimens. As can be seen from the figure, SK is more finegrained. This is due to the fact that during transportation, particles are sorted by size and become rounded; therefore, SK was generally formed of more fine-grained and
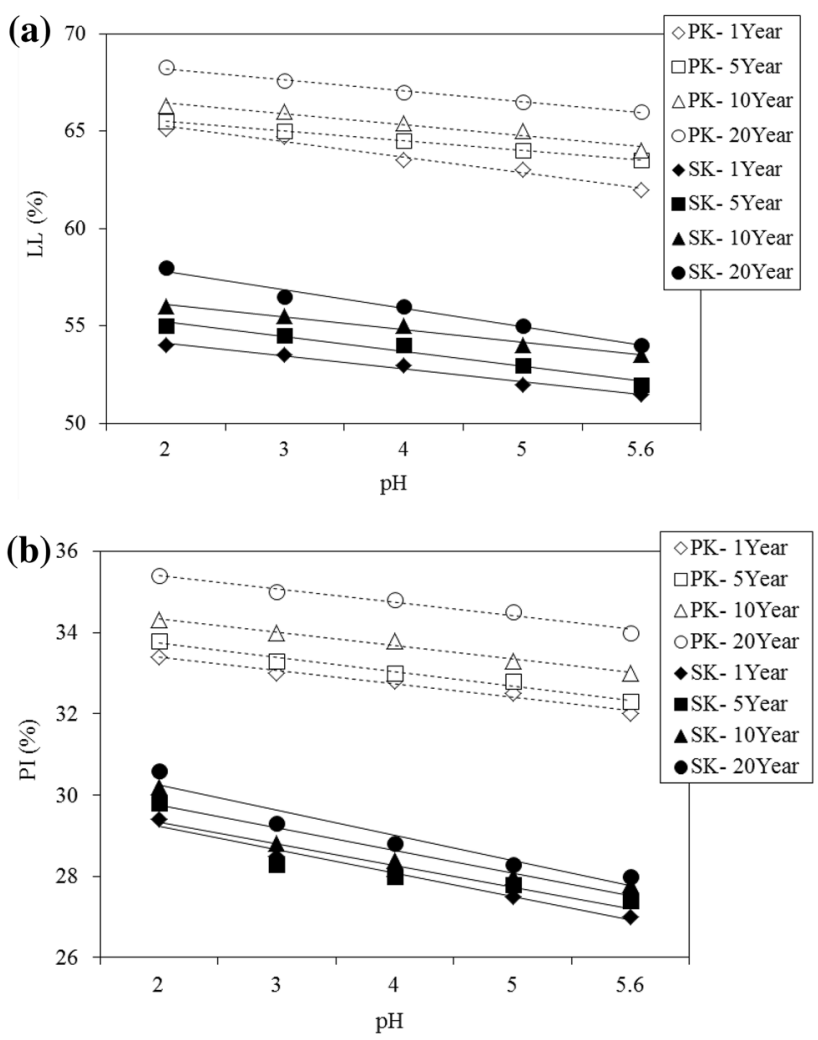

Fig. 6 Consistency limits of PK and SK soils with respect to $\mathrm{pH}$ in flux of SAR 1 year to 20 year a Liquid limit of PK and SK soils with respect to $\mathrm{pH}, \mathbf{b}$ Plasticity index of $\mathrm{PK}$ and $\mathrm{SK}$ soils with respect to $\mathrm{pH}$

aggregated particles than PK [26]. The basic properties of these two soils are listed in Table 1. The liquid limit (LL), specific gravity (GS), and water content (WC) were determined according to BSI 1377-2 [27]. The X-ray diffraction (XRD) patterns confirmed the presence of minerals such as mica, K-Feldspar, and quartz in the PK specimen (Fig. 2); moreover, some minerals such as illite and smectite were recorded for the SK specimens (Fig. 3), confirming the purity of the PK and SK soils $[16,21]$. $\mathrm{X}$-ray fluorescence (XRF) analyses were carried out to confirm the nature of the clays with a Bruker AXS D8Advance diffractometer using $\mathrm{CuKa}$ radiation. XRF data were collected in both samples and measurements were made using a step-scanning technique with a fixed time of $3 \mathrm{~s}$ per $0.028 \mathrm{~h}$.

\section{Simulated Acid Rain Preparation}

To investigate the long-term effect of acid rain intrusion, simulated acid rain (SAR) was prepared by adding a certain volume of $0.005 \mathrm{M}$ nitric acid $\left(\mathrm{HNO}_{3}\right)$ and sulfuric acid $\left(\mathrm{H}_{2} \mathrm{SO}_{4}\right)$ to deionised distilled water. The $\mathrm{pH}$ values of the SAR were adjusted to $2,3,4,5$, and 5.6. The flux of SAR equivalent to annual precipitation was calculated as flux of 
(a)
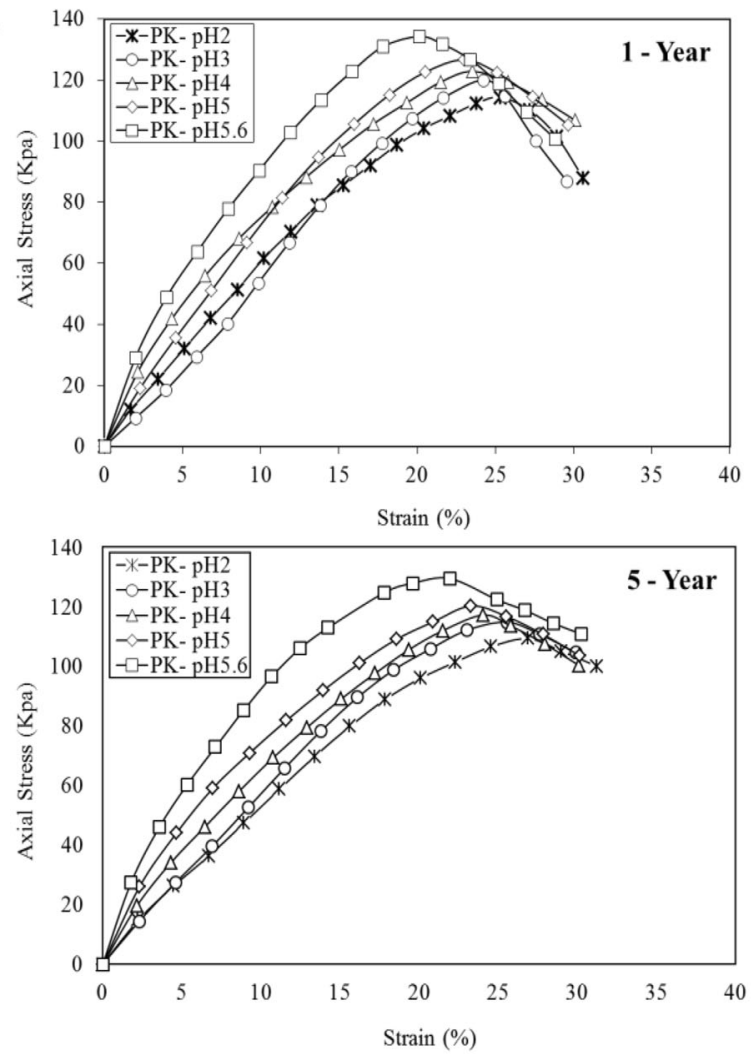

(b)
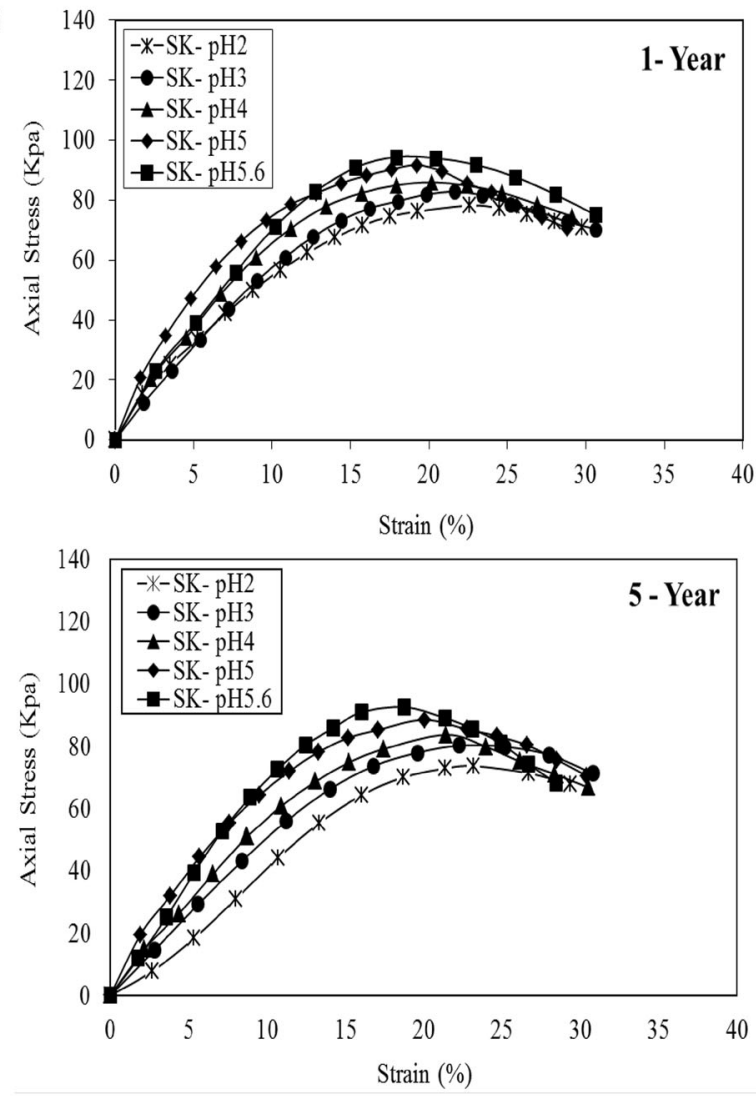
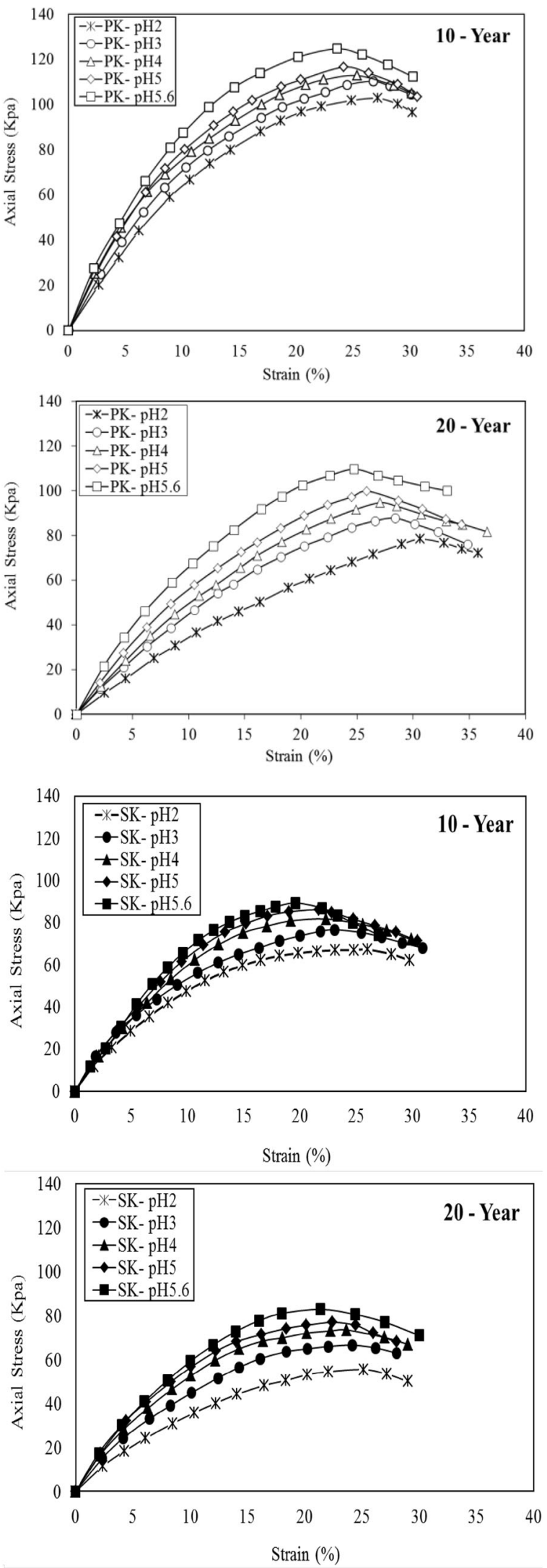

Fig. 7 Stress-strain behaviour of PK and SK samples in flux of SAR 1 year to 20 years, a Stress-strain behaviour of PK, and b Stress-strain behaviour of SK sample 

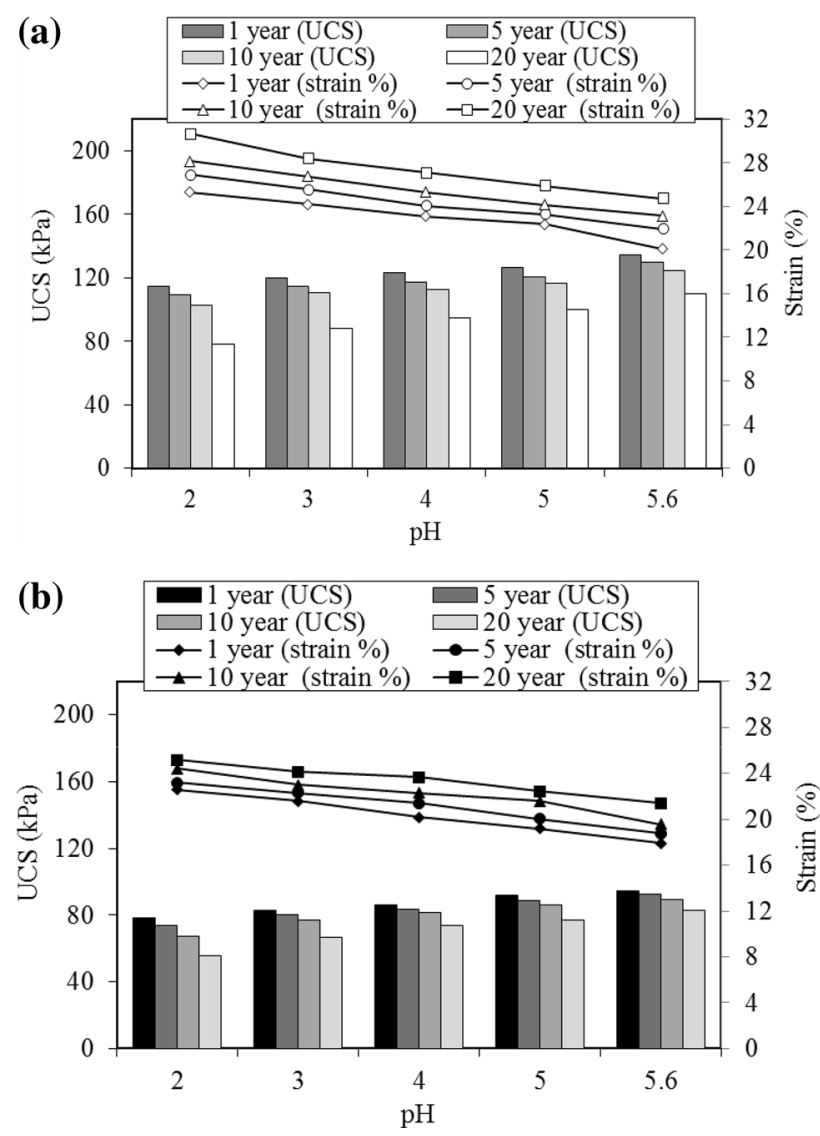

Fig. 8 Devolution of compressive strength of PK and SK samples with respect to $\mathrm{pH}$ in flux of SAR 1 year to 20 year a Compressive strength of PK, b Compressive strength of SK

SAR $=1 / 3 R_{\text {ave }} A$, where ' $R$ ' ave stands for annual average precipitation, and 'A' stands for the cross-sectional area of the specimen. The flux of the SAR was determined based upon the average annual precipitation in Malaysia (i.e. $2400 \mathrm{~mm}$ ) provided by the Malaysia Meteorological Organisation $[25,26]$. It was assumed that one-third of the precipitation will infiltrate into the ground [27]. Therefore, the SAR fluxes equivalent to precipitation for 1, 5, 10 and 20 years were determined to be equal to $1.57,7.85,15.70$, and 31.41 , respectively.

\section{Infiltration Tests and Ground Engineering Properties}

In order to investigate the effect of SAR on unconfined compressive strength (UCS), the soil specimens were prepared at MDD and OMC using a mini compaction apparatus with a diameter of $50 \mathrm{~mm}$ and height of $100 \mathrm{~mm}$, devised by Sridharan and Sivapulliah [28]. Afterward, the soil specimen was extruded and placed into the infiltration cells. The infiltration setup was fabricated as shown in Fig. 4. The setup consisted of transparent PVC pipes with two different dimensions including an internal diameter of $50 \mathrm{~mm}$, height $100 \mathrm{~mm}$; and internal diameter of $100 \mathrm{~mm}$, height $50 \mathrm{~mm}$. To confine the soil samples, a surrounding membrane was used to keep the soil and two caps at the top and bottom of the specimen, in order to ensure there was no leach out of SAR from the soil. To inject the SAR to the soil, a tank was connected to the top cap using a pipe and control valve. The samples were then infiltrated by different $\mathrm{pH}$ levels of the SAR for different fluxes of SAR, equivalent to precipitation for $1,5,10$, and 20 years.

The UCS tests were performed on treated specimens in according to BSI 1377-7 [27]. Thereafter, the Atterberg limits of the samples were measured at varying values of pH using the Casagrande method according to BSI 1377-2 [27]. Also, the infiltration setup was slightly modified to measure the hydraulic conductivity by falling head method [29]. Furthermore, the Proctor compaction test was carried out on treated specimens using a mini compaction apparatus devised by Sridharan and Sivapullaiah [28]. Moreover, the specific gravity test was determined on PK and SK samples at $\mathrm{pH} \mathrm{2,} \mathrm{3,} \mathrm{4,} \mathrm{5,} \mathrm{and} 5.6$ and at different fluxes of SAR equivalent to precipitation for 1-20 years in accordance with BS 1377-2 [27].

In order to investigate the effect of SAR on the compressibility behavior of soil, the soil specimen was prepared at MDD and OMC. Afterward, the soil specimen was extruded and placed into the exposure cell. The exposure cell was similar to that shown in Fig. 3. The sample was then infiltrated by different $\mathrm{pH}$ levels of the SAR for different fluxes. Finally, the specimens with diameter $10 \mathrm{~cm}$ were carefully cut into smaller specimens with height $20 \mathrm{~mm}$. Consolidation tests were performed in an a one-dimensional oedometer according to BS 1924: Part 2-Sect. 4 [27]. Overburden stress was applied in increments of $25,50,100,200,400$, and $100 \mathrm{kPa}$, followed by unloading. The compression index $\mathrm{Cc}$, the slope of the virgin compression curve, was computed as: $\mathrm{Cc}=(\mathrm{e} 100 \mathrm{kPa}-\mathrm{e} 400 \mathrm{kPa}) /(\log (400 \mathrm{kPa} / 100 \mathrm{kPa}))$, where "Cc" is compression index and " $\mathrm{e}$ " is void ratio.

\section{Zeta Potential Test}

In order to prepare the specimens for zeta potential $(\zeta)$ measurement at varying values of $\mathrm{pH}$ of 2, 3, 4, 5 and 5.6, the PK and SK samples infiltrated by SAR were dried at $80{ }^{\circ} \mathrm{C}$ for $48 \mathrm{~h}$. They were then sieved through a No. 100 $(150 \mu \mathrm{m})$ size sieve. A $15 \mathrm{mg}$ specimen was then transferred into $50 \mathrm{~mL}$ aqueous solution, and magnetic stirring bars were subsequently added. The $\mathrm{pH}$ adjustments were performed using dilute $\mathrm{HNO}_{3}$ and $\mathrm{H}_{2} \mathrm{SO}_{4}$ [30]. The $\zeta$ was measured by Malvern Zetasizer 3000HSA (Malvern Instruments, Ltd.) equipped with a microprocessor unit. 
Fig. 9 Influence of $\mathrm{pH}$ on void ratio-effective vertical stress relationship in flux of SAR 1 year to 20 year a $\mathrm{pH}$ on void ratio-effective vertical stress of $\mathrm{PK}, \mathbf{b} \mathrm{pH}$ on void ratio-effective vertical stress of SK
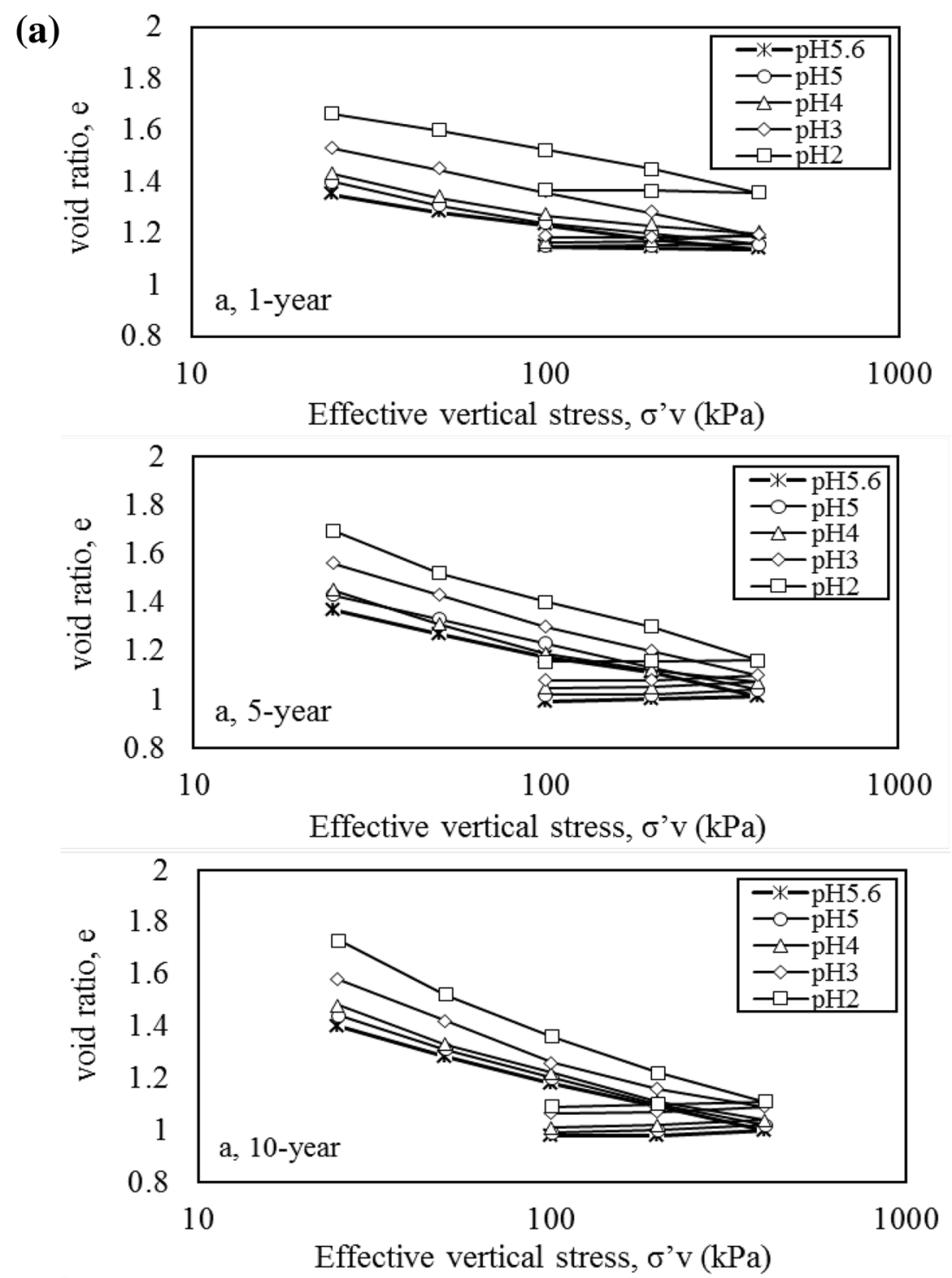

\section{Atomic Adsorption Spectroscopy}

The atomic adsorption spectroscopy (AAS) technique was used to measure the concentration of elements (i.e. Al, Fe, $\mathrm{Si}, \mathrm{K}$, and $\mathrm{Ca}$ ) in soil infiltrated by different $\mathrm{pH}$ levels of the SAR for different fluxes of SAR. $0.05 \mathrm{~g}$ of soil infiltrated by SAR was oven-dried at $105{ }^{\circ} \mathrm{C}$ for $4 \mathrm{~h}$. Afterwards, the soil powders were mixed with $100 \mathrm{ml}$ HCL $65 \%$ (Merck). The aqueous solution was then thoroughly stirred for $2 \mathrm{~h}$. Finally, the traced elements were measured 
Fig. 9 continued

(b)
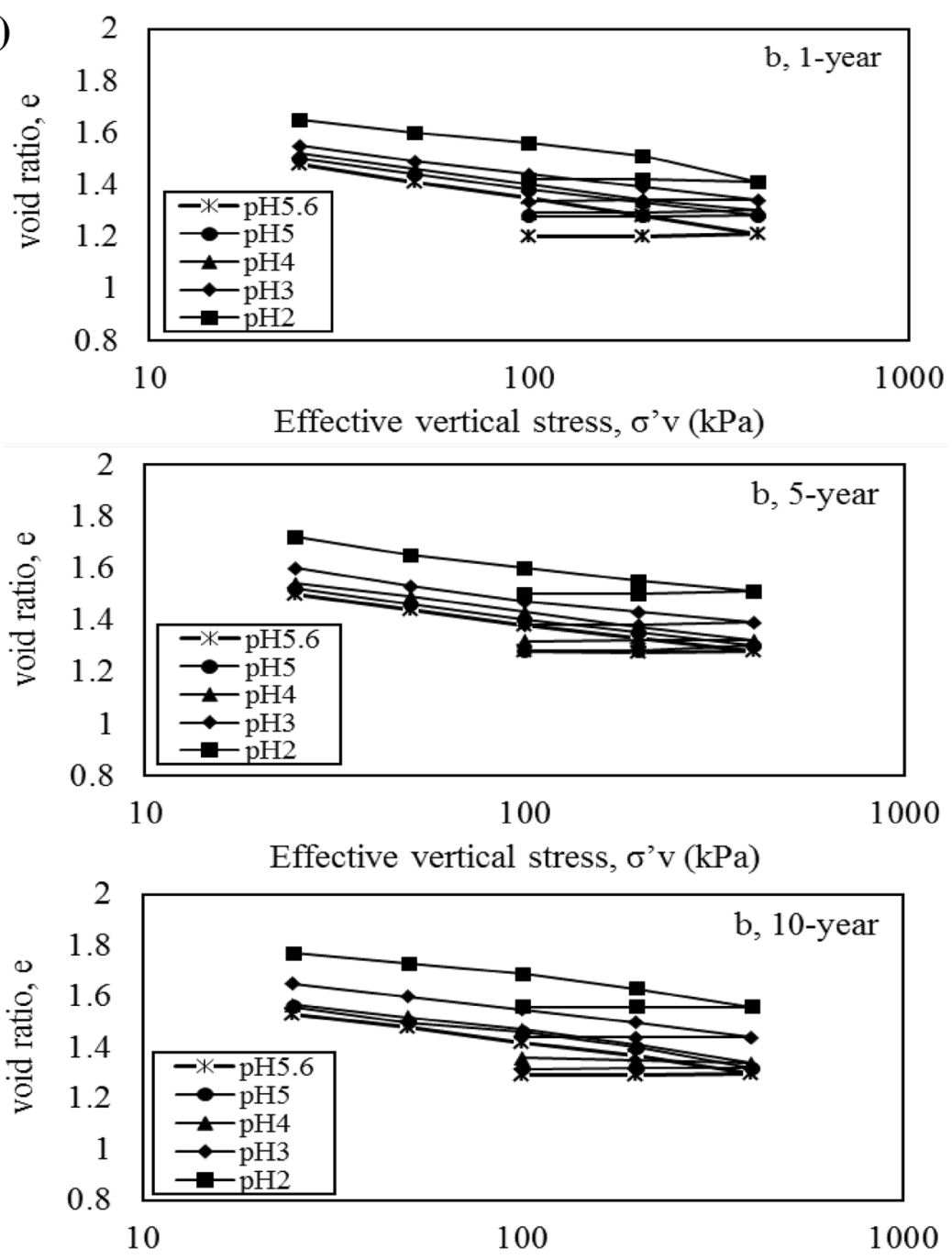

Effective vertical stress, $\sigma^{\prime} \mathrm{v}(\mathrm{kPa})$

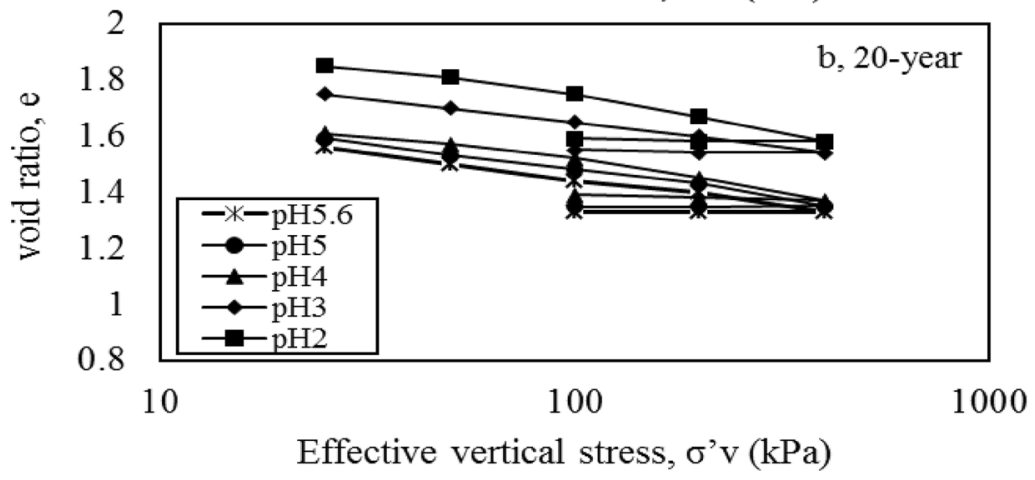

by AAS. Also, the concentration of elements in the outflow water leached from the PK and SK was measured with the same technique.

In addition, the water extraction method was used to measure the basic soluble cations of soil infiltrated by different $\mathrm{pH}$ levels of the SAR for the different fluxes. The extracted solution was then analyzed by AAS for the soil cations [31].

\section{Scanning Electron Microscope and Energy Dispersive X-ray Spectroscopy}

Scanning electron microscope (SEM) analyses and energy dispersive X-ray spectroscopy (EDX) were carried out to understand the underlying mechanisms of the effects of acid rain on the studied soils, before and after the treatment of soil by SAR at $\mathrm{pH} 2$ for different fluxes of SAR. 

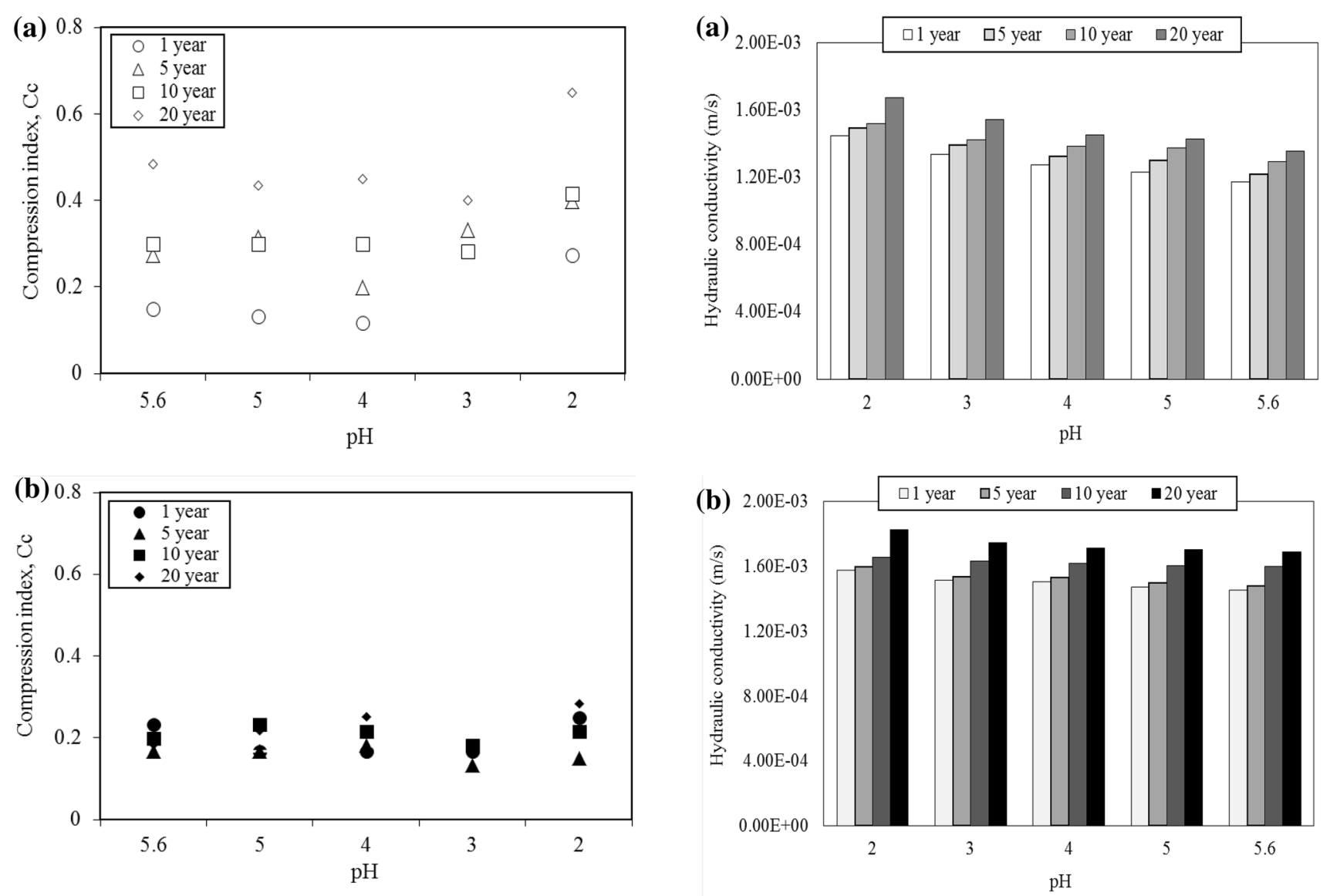

Fig. 10 Influence of $\mathrm{pH}$ on compression index in flux of SAR 1 year to 20 year a PK sample, b SK sample

\section{Results and Discussion}

\section{Specific Gravity Results}

Specific gravity calculations [27] were performed by determining the ratio of slurry weight to water weight required to fill a graduate cylinder. Figure 5 shows the ranges of variation of $G_{s}$ in both samples. It is seen that the $\mathrm{G}_{\mathrm{s}}$ decreased for both the PK and SK specimens when the $\mathrm{pH}$ value decreased and the flux of SAR increased. The highest $\mathrm{G}_{\mathrm{s}}$ value in both kaolinite clays was recorded at $\mathrm{pH}$ 5.6 when both samples were infiltrated by a flux of SAR equivalent to precipitation for 20 years. It was observed that the effect of the flux of SAR for the PK specimen was much more than that of the SK specimen.

\section{Atterberg Limits Results}

Figure 6a shows the result of LL of the PK and SK samples, with the effect of different $\mathrm{pH}$ values for different fluxes of SAR. As can be seen from the figure, LL increased with a decrease of $\mathrm{pH}$ value for all fluxes of SAR and all $\mathrm{pH}$ levels. The highest LL of 68 and $58 \%$ were

Fig. 11 Hydraulic conductivity of PK and SK soils with respect to $\mathrm{pH}$ a Hydraulic conductivity of PK in flux of SAR 1 year to 20 years, b Hydraulic conductivity of SK in flux of SAR 1 year to 20 years

recorded for PK and SK at $\mathrm{pH} 2$, when both samples were infiltrated by a flux of SAR equivalent to precipitation for 20 years. It should be noted that the range of variations of LL in the PK soil is slightly greater than that of the SK samples.

Figure $6 \mathrm{~b}$ shows the variation of plasticity index (PI) in both samples. It can be seen that the PI increased for both samples when the $\mathrm{pH}$ value decreased and the flux of SAR increased. The highest PI value was recorded at $\mathrm{pH} 2$ when both samples were infiltrated by a flux of SAR equivalent to precipitation for 20 years. It was also observed that the effect of the flux of SAR for the PK specimen was much greater than that of the SK specimen.

\section{Unconfined Compression Results}

Figure 7 shows the stress-strain behaviour of the PK and SK specimens influenced by SAR for the different fluxes. As can be seen from the figure, the PK and SK specimens infiltrated by a flux of SAR equivalent to precipitation for 1 year at $\mathrm{pH} 2$ exhibited peak strength of 114 and $78 \mathrm{kPa}$ at 

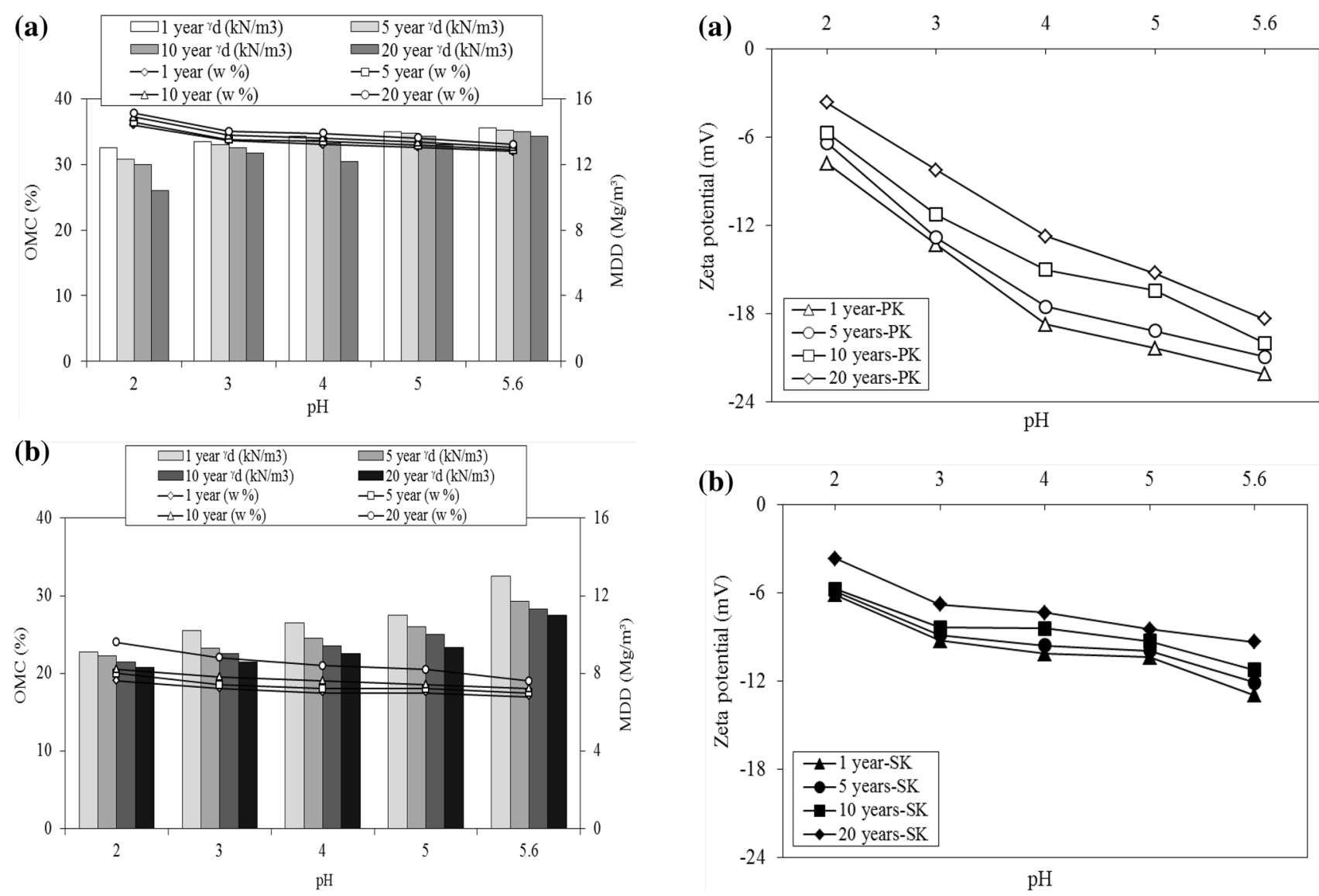

Fig. 12 Compaction characteristics of PK and SK soils with respect to $\mathrm{pH}$ a Compaction characteristics of $\mathrm{PK}$ in flux of SAR 1 year to 20 years, $\mathbf{b}$ Compaction characteristics of SK in flux of SAR 1 year to 20 years

failure strains of 25 and $22 \%$ respectively. However, the peak strength decreased to 78 and $55 \mathrm{kPa}$ at failure strains of 30 and $25 \%$ respectively, as the flux of the SAR increased to that of 20 years at $\mathrm{pH} 2$. Similar behaviour for the peak strength was observed for the PK and SK samples infiltrated by SAR at different $\mathrm{pH}$ levels, when the fluxes of the SAR increased to that of 20 years. The results showed that the rate of strength loss for the PK sample was higher than that of the SK sample as the fluxes of the SAR increased from 1 year to 20 years.

Figure 8 shows the devolution of compressive strength and strain at failure with respect to $\mathrm{pH}$ level of SAR for the PK and SK samples, respectively. The highest rate of strength loss was recorded at about 78 and $55 \mathrm{kPa}$ for the PK and SK samples, respectively, when the specimen was infiltrated by SAR at $\mathrm{pH}$ of 2 with a flux equivalent to 20 years. Furthermore, in both the PK and SK samples, the strain at failure increased as the $\mathrm{pH}$ level decreased or as the flux of SAR increased. The highest failure strains for both PK and SK samples infiltrated with a flux of SAR equivalent to 20 years were recorded as 30 and $25 \%$,

Fig. 13 Zeta potential of soils with respect to $\mathrm{pH}$ in flux of SAR 1 year to 20 years a PK sample, b SK sample

respectively. The results revealed that for both the PK and SK samples, a lower $\mathrm{pH}$ level of the SAR and higher fluxes of SAR could change the behaviour of clay minerals to be more brittle and with a lower compressive strength. However, the rate of change for the PK sample was observed to be higher than that of the SK sample.

\section{One-Dimensional Consolidation Results}

The laboratory results indicated that the SAA had a strong influence on the compressibility behaviour of the specimens. It was observed that the uppermost virgin compression curve in PK and SK had the lowest $\mathrm{pH}$ value of 2 . The initial void ratio of PK and SK increased as the $\mathrm{pH}$ decreased or the flux of SAR increased. For instance, in PK and SK at $\mathrm{pH} 2$ with the flux of SAR for 20 years, the value of void ratio was 1.93 and 1.85 , respectively. On the other hand, for the same $\mathrm{pH}$ at 1 year, the initial void ratios were 1.67 and 1.63 respectively, which may be the result of the longer exposure to the SAR (Fig. 9).

Figure 10 shows the evolution of compression index, $\mathrm{Cc}$, at different $\mathrm{pH}$ levels and at for a variety of fluxes of 
(a)
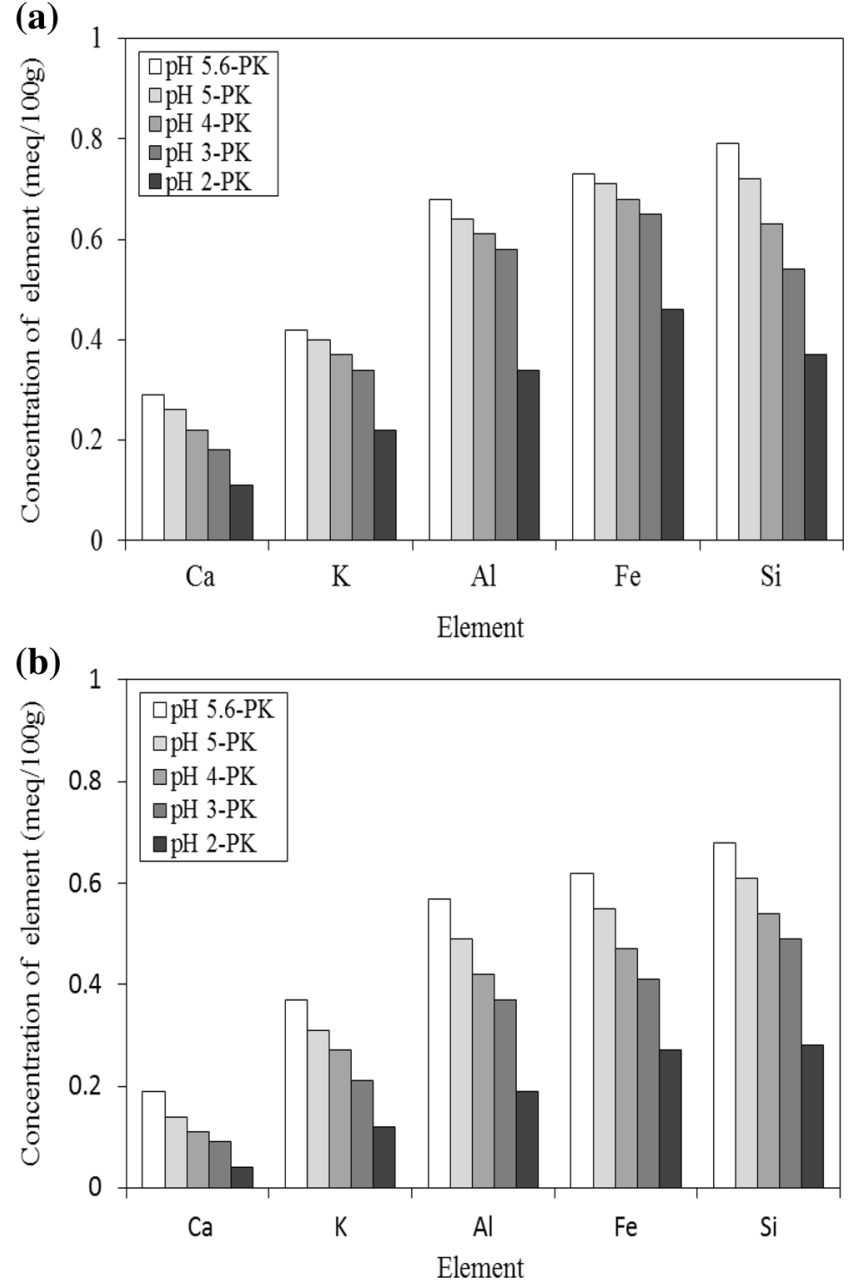

(c)

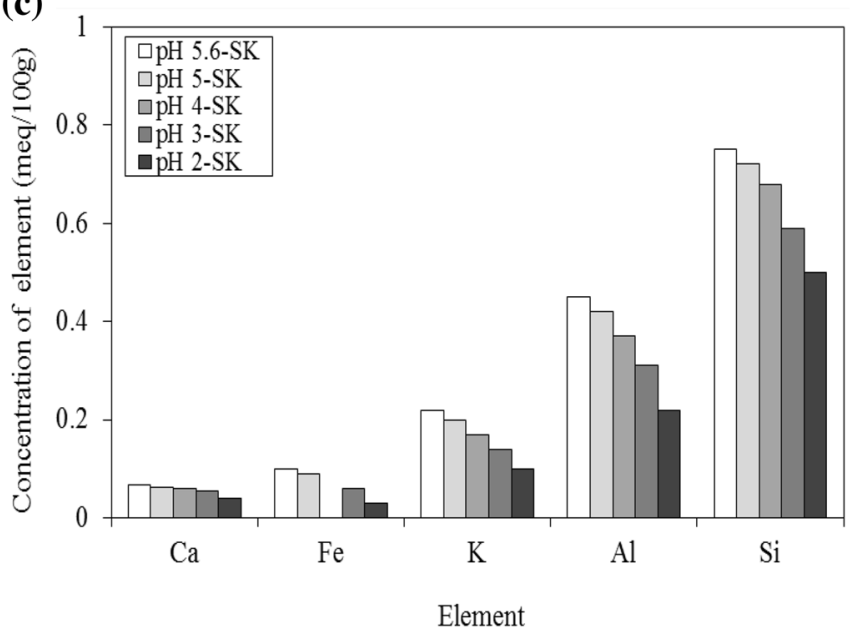

(d)

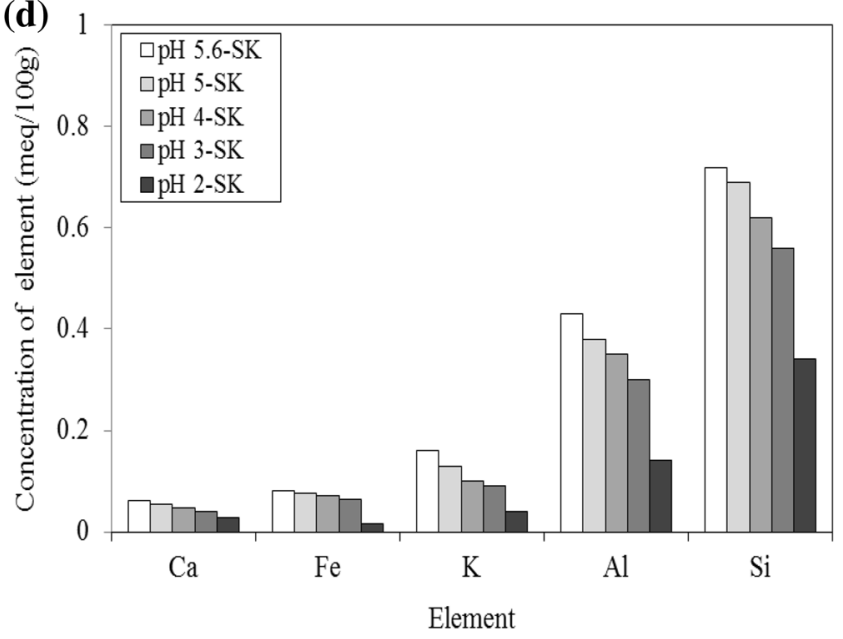

Fig. 14 AAS analysis of soil before and after filtration by SAR in flux of 1 year and 20 year a PK-1 year, b PK-20 years, c SK- 1 year, and d SK-20 years with respect to $\mathrm{pH}$

SAR for 1, 5, and 20 years in the PK and SK specimens. Figure 10 shows that $\mathrm{Cc}$ can significantly increase as the environment becomes more acidic. For instance, the highest value of $\mathrm{Cc}$ was recorded to be about 0.64 and 0.28 for the PK and SK samples, respectively, when the specimen was infiltrated by SAR at $\mathrm{pH}$ of 2 with the flux equivalent to 20 years. It is clear from the figures that the effect of low $\mathrm{pH}$ values had a more pronounced influence on $\mathrm{Cc}$ for both specimens. It was observed that the increase in compressibility behaviour was in agreement with the increase in LL and the reduction in compressive shear strength of both the PK and SK specimens.

\section{Hydraulic Conductivity Results}

The change in hydraulic conductivity values against the permeated fluxes of SAR is shown in Fig. 11. The results confirmed that the hydraulic conductivity increased with a decrease in $\mathrm{pH}$ value and increase of fluxes of SAR. The hydraulic conductivity of both the PK and SK specimens increased by 15 and $13 \%$, respectively, at $\mathrm{pH} 2$, when the samples were infiltrated by a flux of SAR equivalent to precipitation for 20 years, which is consistent with the results of unconfined compressive strength. The increase in hydraulic conductivity of both samples could be attributed to the small increase of the void ratio (i.e. a decrease in the dry density) and possibly due to decrease in diffuse double layer thickness during the test.

\section{Compaction Results}

The PK and SK specimens initially showed an MDD and OMC of $1.12 \mathrm{Mg} / \mathrm{m}^{3}$ and $32 \%$, and $1.04 \mathrm{Mg} / \mathrm{m}^{3}$ and $36 \%$ respectively (see Table 1). Figure 12 shows the compaction characteristics of the PK and SK specimens influenced by different $\mathrm{pH}$ levels and different fluxes of SAR. 

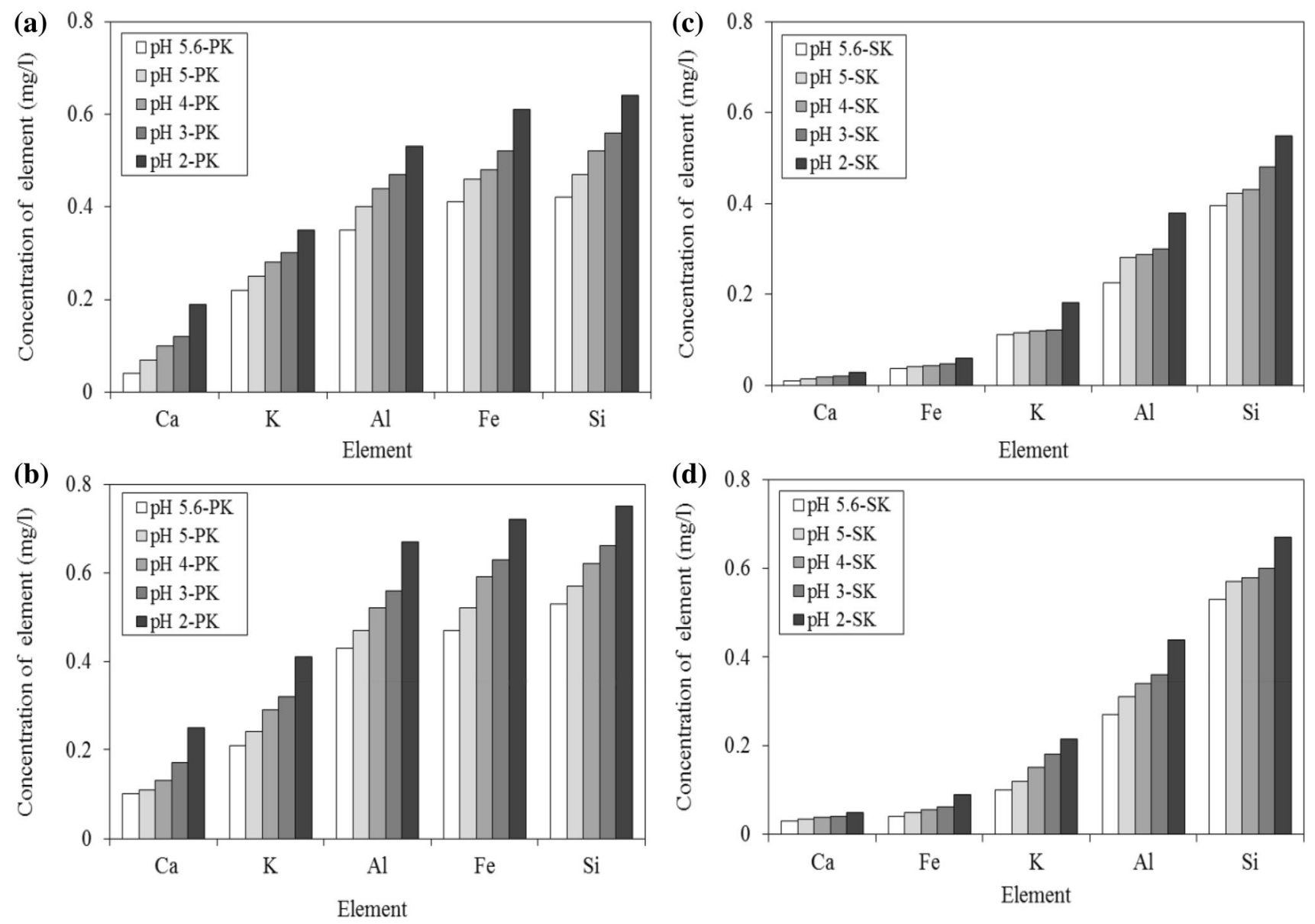

Fig. 15 AAS analysis of leachate from a PK-1 year, b PK -20 years, c SK -1 year, d SK- 20 years, with respect to pH

As can be seen from the figure, infiltration of SAR into both specimens led to decreased MDD and increased OMC. The lowest MDD and the highest OMC were observed when the specimens were infiltrated by a flux of $\mathrm{SAR}$ equivalent to precipitation for 20 years at $\mathrm{pH} 2$. It was also observed that the PK specimen showed slightly higher changes compared to the SK specimen. This behaviour is consistent with the Atterberg limits behaviour (Fig. 5).

\section{Zeta Potential Results}

Figure 13 indicates the zeta potential $(\zeta)$ of specimens in the presence of SAR at different $\mathrm{pH}$ values. As can be seen from the figure, $\zeta$ of $\mathrm{PK}$ and $\mathrm{SK}$ decreased as the $\mathrm{pH}$ dropped from 5.6 to 2 . It should be noted that the surface charge of kaolinite clay is $\mathrm{pH}$-dependent [32-34]. The $\mathrm{pH}-$ dependent negative surface charge of kaolinite clay can be attributed to the dissociation of $\mathrm{OH}^{-}$groups on clay edges [33]. As can be seen, the effect of $\mathrm{pH}$ on $\zeta$ of $\mathrm{PK}$ was slightly higher than for the SK specimens.

From clay colloid chemistry [35], it is also known that this ion exchange process would lead to an increase in equivalent diffuse double layer thickness. Nevertheless, this process is likely to have fewer effects on mechanical changes in both the PK and SK samples. This can be explained by the fact that kaolinite clay does not develop sufficient diffuse double layer repulsive force to influence the changes in the engineering properties $[13,14,36]$.

The zeta potential, $\zeta$, measurements showed that the surface charge of both minerals was $\mathrm{pH}$-dependent (Fig. 13). It was confirmed that, under the effects of SAR, the zeta potential of both minerals decreased. This indicates a relatively flocculated fabric for the kaolinite clay particles with dominant edge-to-face particle associations [14] that resulted in a reduction in soil strength and, consequently, the observed changes in Atterberg limits and compaction characteristics.

\section{Results from Atomic Adsorption Spectroscopy}

The atomic adsorption spectrometry (AAS) analysis in Fig. 14 shows the elemental concentrations of soil before and after filtration by SAR. The results show that the concentration of trace elements in PK and SK significantly decreased when the specimens were influenced by different fluxes of SAR at different pH levels. In order of abundance 

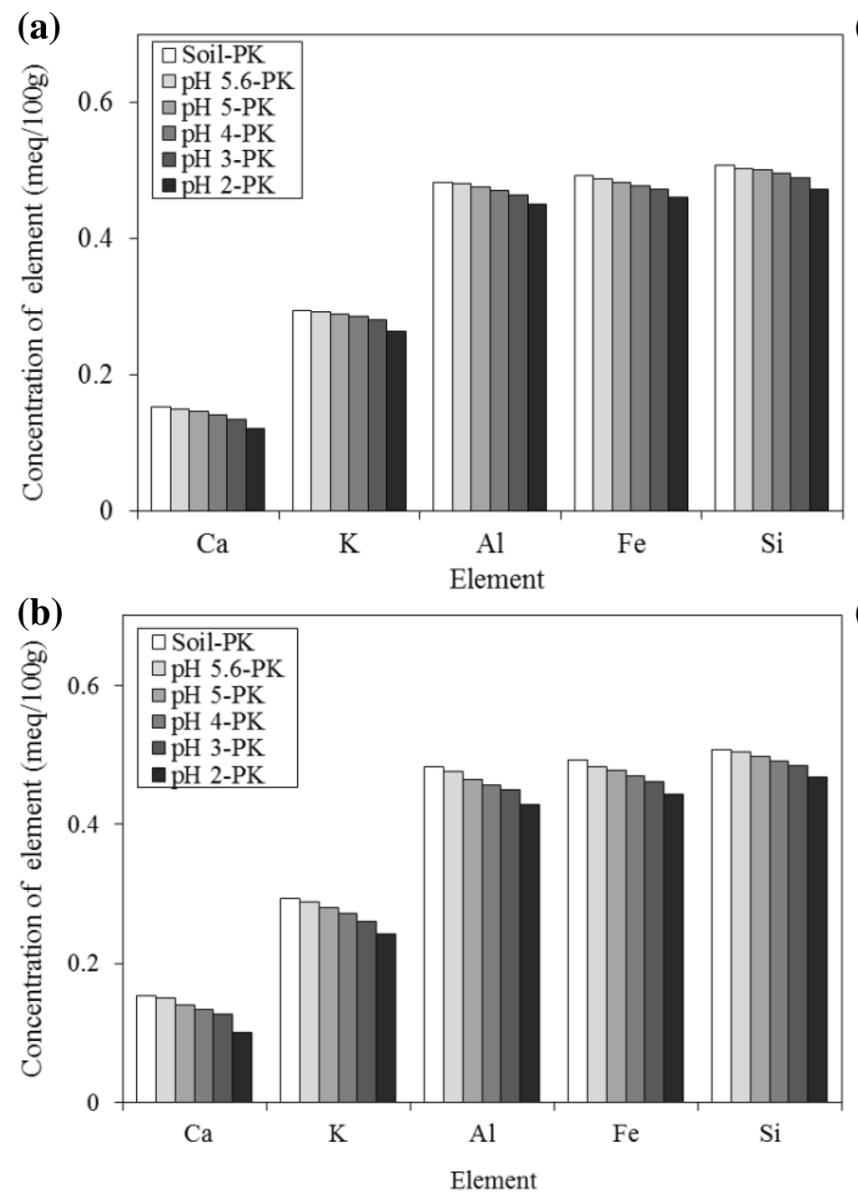

(c)

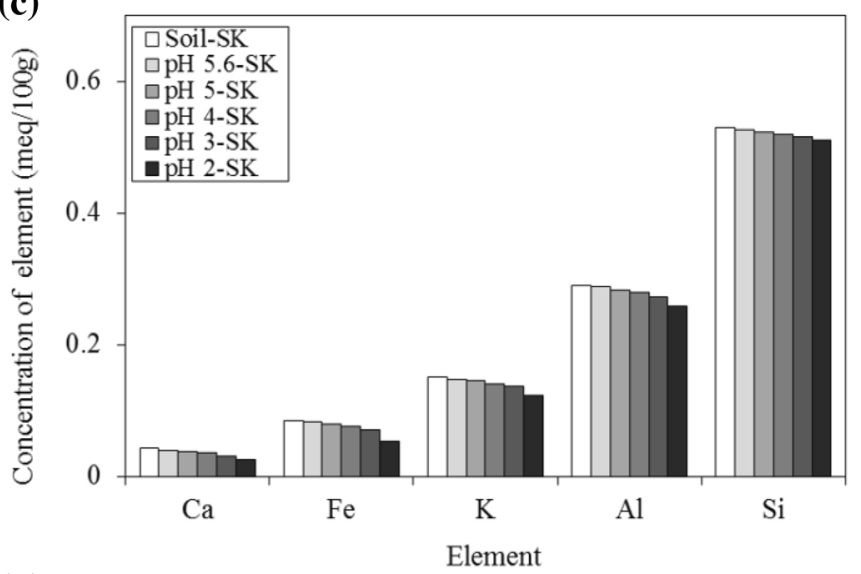

(d)

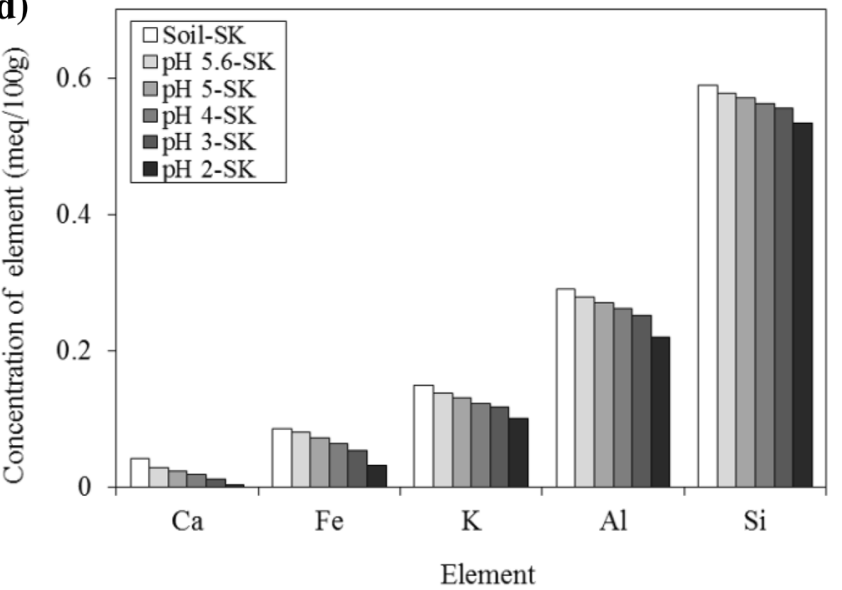

Fig. 16 Ion-soluble analysis of soil before and after filtration by SAR a PK -1 year, b PK -20 years, c SK-1 year, and d SK-20 years, with respect to $\mathrm{pH}$

in the PK and SK specimens (see Table 1), from most to least, the major constituents were: $\mathrm{Si}, \mathrm{Fe}, \mathrm{Al}$, and $\mathrm{K}$; and $\mathrm{Si}$, $\mathrm{Al}, \mathrm{K}$, and $\mathrm{Fe}$, respectively. The concentration of $\mathrm{Fe}, \mathrm{Al}$, and $\mathrm{Si}$ in PK and SK, for example, decreased by around $0.46,0.34$ and $0.37 \%$; and $0.03,0.22$, and $0.05 \%$ respectively, when the soils were infiltrated by a flux of $\mathrm{SAR}$ equivalent precipitation for 1 year at $\mathrm{pH} 2$. In particular, the greatest reduction in the concentration of $\mathrm{Fe}$ and $\mathrm{Al}$ was observed for PK and SK when the specimens were infiltrated by a flux of SAR equivalent to precipitation for 20 years at $\mathrm{pH} 2$. A comparison between the PK and SK specimens shows that both clay minerals had low $\mathrm{pH}$ and high potential leaching rates, due to their having low CEC and a lack of basic chemicals; consequently, the effects of SAR were pronounced due to the lower buffering capacity of the soils [37]. It is believed that the movement of SAR through the PK and SK soils dissolves most of the elements, leaching them out of the samples in the infiltration test.
Figure 15 shows the SAS analysis of outflow fluid leached from PK and SK. As can be seen, there was a general increase in the sum of total cations as a result of increasing the flux and decreasing the $\mathrm{pH}$ level of the SAR. The results indicate a correspondence between the variation of the elemental concentrations of soil and the cations in outflow fluid leached from PK and SK. The study of the test results of both clays show that the concentration of elements leached from PK and SK depended on the types of the element, $\mathrm{pH}$ and flux of SAR.

Figure 16 shows the concentration of soluble cations before and after infiltration by SAR. As can be seen, there was a general decrease in the amounts of soluble ions between particles, as a result of increasing the flux and also decreasing the $\mathrm{pH}$ level of the SAR. The results showed that the greatest reduction in the concentrations of $\mathrm{Fe}$ and Al was observed for PK and SK when the minerals were infiltrated by a flux of SAR equivalent to precipitation for 20 years at $\mathrm{pH} 2$. 

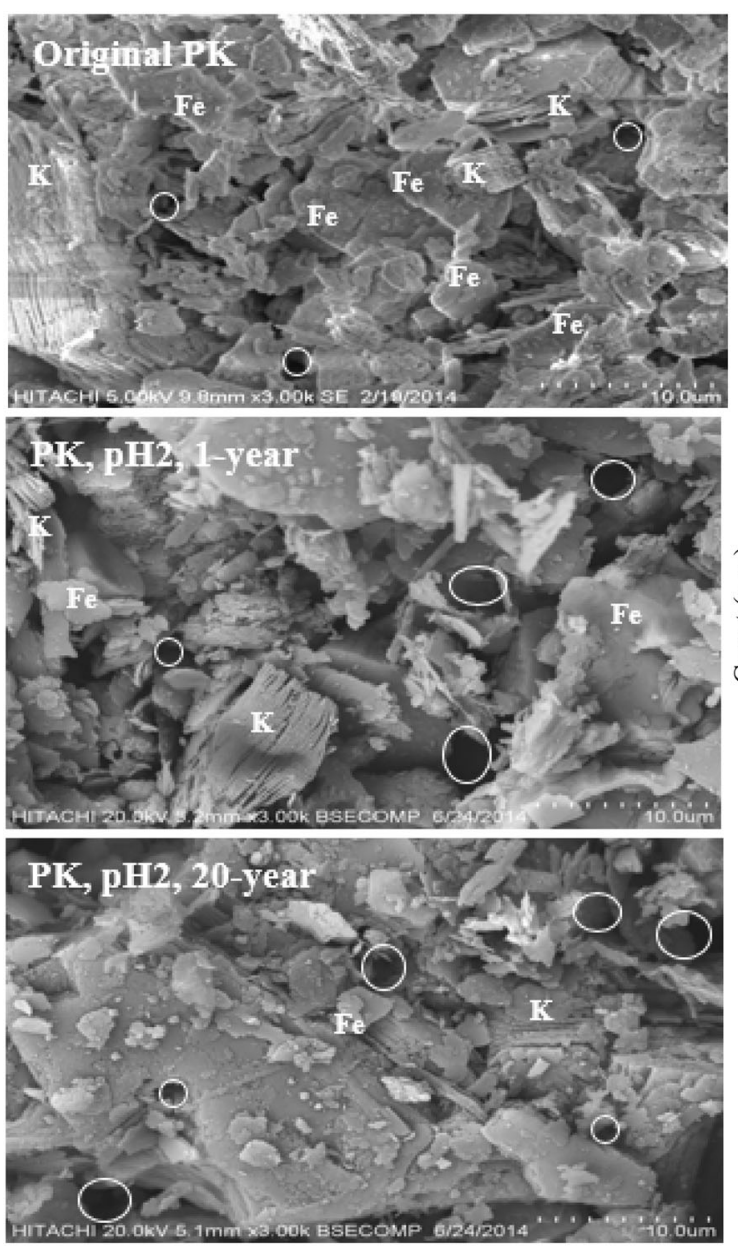

(a)
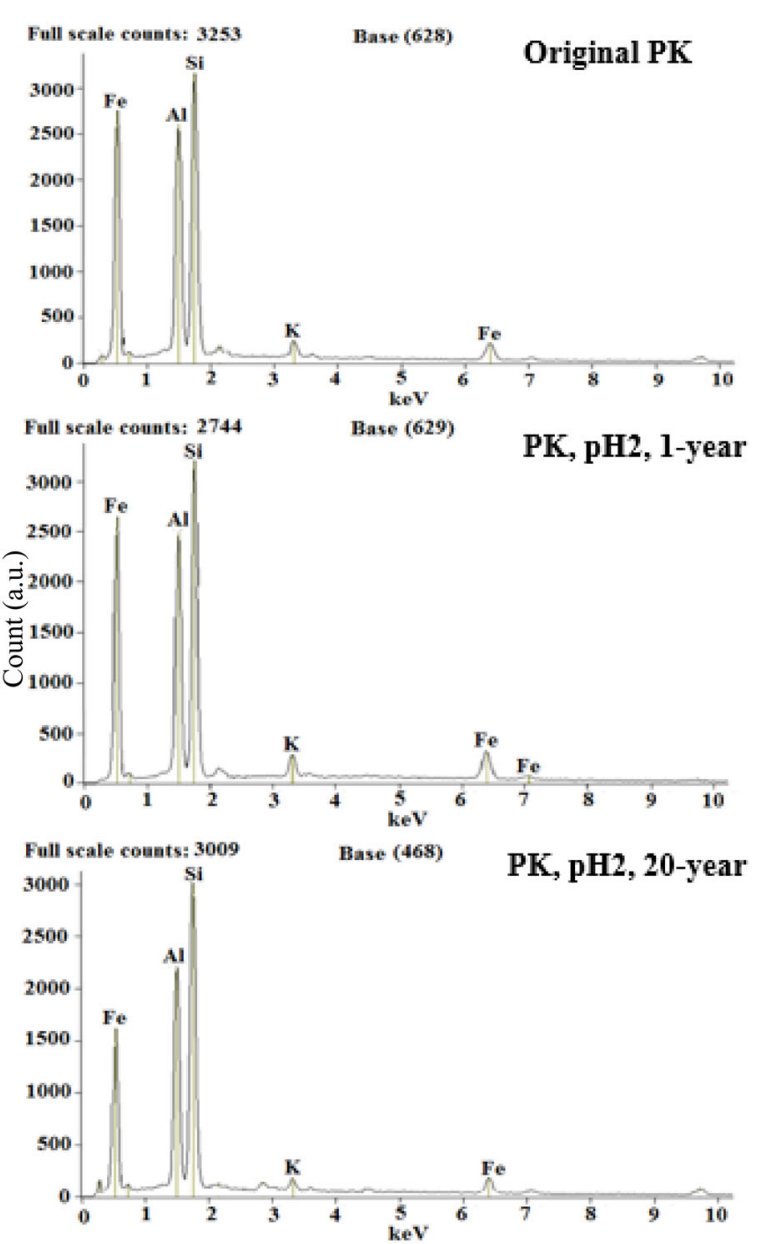

(b)

Fig. 17 SEM and EDX analyses of PK in original conditions and pH 2 in flux of SAR 1 year to 20 years a SEM images, b EDX images

When the specimens became acidic, the hydrogen ions $\left(\mathrm{H}^{+}\right)$from SAR engage in an exchange process with the cations present. Due to its superior position in the Hofmester series, $\mathrm{H}^{+}$would replace $\mathrm{Fe}^{3+}$ and $\mathrm{Al}^{3+}$. Figures 13 and 14 clearly confirmed that most of the traced elements and cations, including $\mathrm{Fe}^{3+}$ and $\mathrm{Al}^{3+}$, were leached out from the matrix when the $\mathrm{pH}$ decreased. Moreover, SAR consisted of a mixture of nitric acid and sulfuric acid, which is known as a strong oxidiser due to the electron donor property of $\mathrm{NO}_{3}^{-}$ and $\mathrm{SO}_{4}^{2-}$ ions in the acidic media, causing a conversion from $\mathrm{Fe}^{2+}$ to $\mathrm{Fe}^{3+}$, and expediting the leaching of $\mathrm{Al}^{3+}$ and $\mathrm{Fe}^{3+}$ in the acidic media. A decrease in iron and aluminum content means the destruction of soil structure: consequently, the shear strength, MDD, and specific gravity decreased, while the OMC, PI, and LL increased.

\section{EDX and SEM Analysis}

Figures 17 and 18 show SEM and EDX analyses of the PK and SK samples before and after treatment at $\mathrm{pH} 2$ of the
SAR for different fluxes of SAR equivalent to precipitation for 1 and 20 years. As can be seen from the SEM results, the PK and SK samples consisted of some large particle packs; clay particles cohered together in the presence of water, therefore forming large particle packs and a densified soil matrix. After SAR treatment, some large spaces between clay particles appeared and disintegration increased as the flux of SAR increased from 1 to 20 years.

The EDX results revealed that after SAR treatment, most of the minerals were leached out from the clay particles due to the infiltration of specimens by SAR. Very large spaces between clay particles in the specimens in the SEM results are attributed to the washing and leaching out of $\mathrm{Al}^{2+}, \mathrm{Fe}^{3+}, \mathrm{Si}^{2+}$, and $\mathrm{K}^{+}$from the clay particles during infiltration. The original PK had a high content of iron and aluminum: about 2800 and 2600 count (a.u.) respectively. The results illustrated that the $\mathrm{Fe}$ and $\mathrm{Al}$ content decreased to 64 and $72.1 \%$ in the PK sample, respectively. The presence of free iron oxide and aluminum oxide has an important role in cementation in clay particles, which 

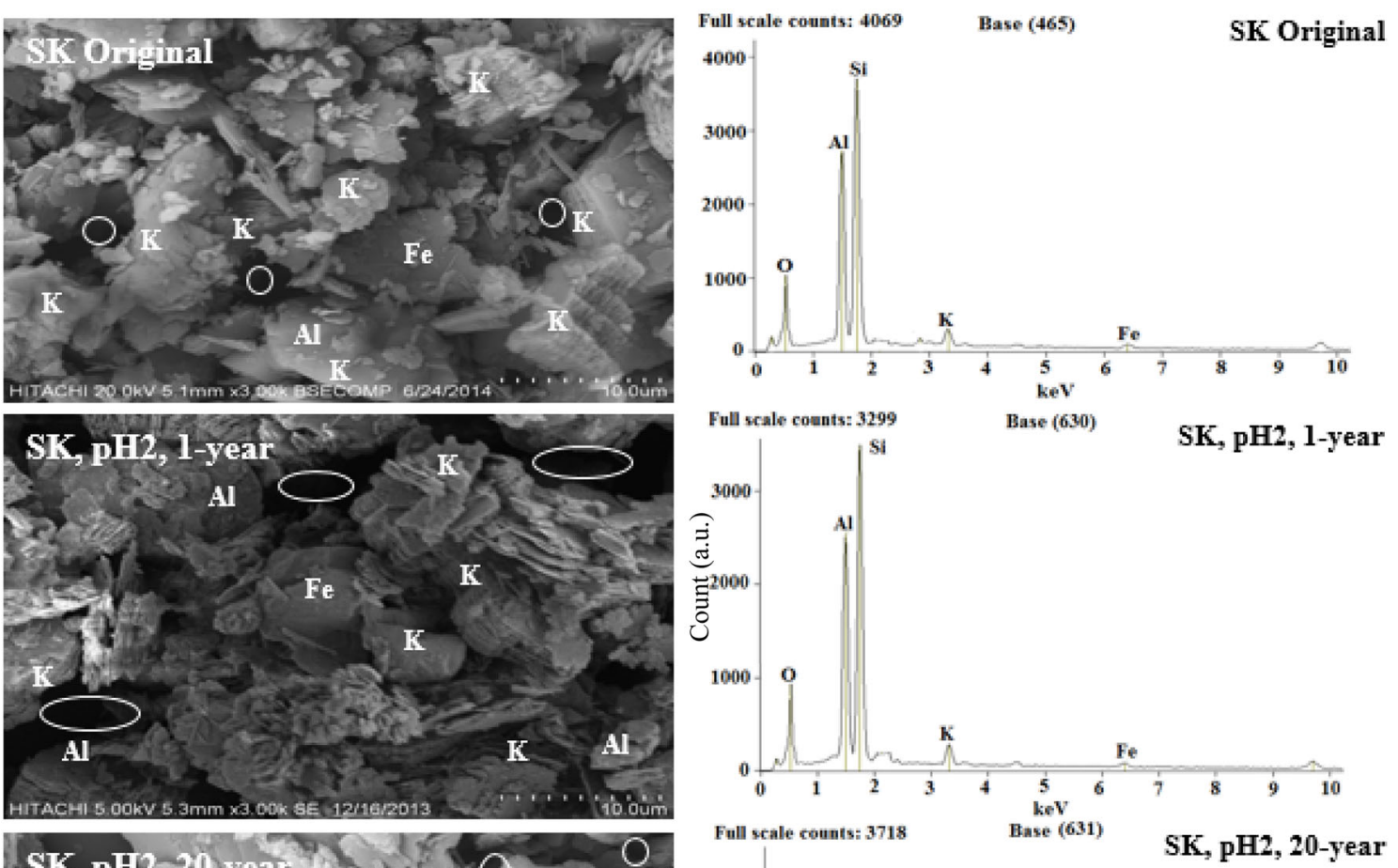

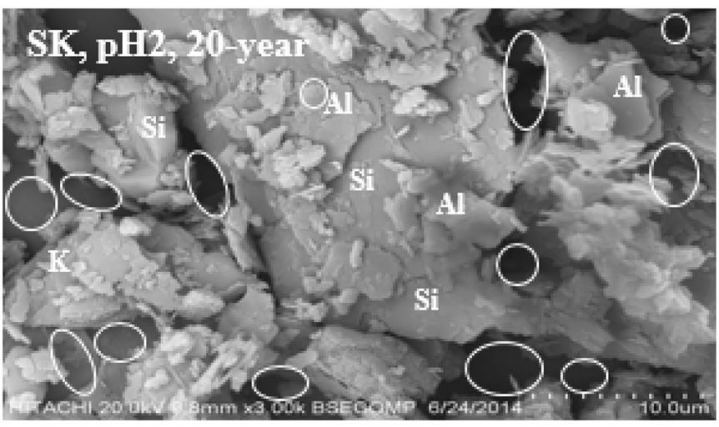

(a)

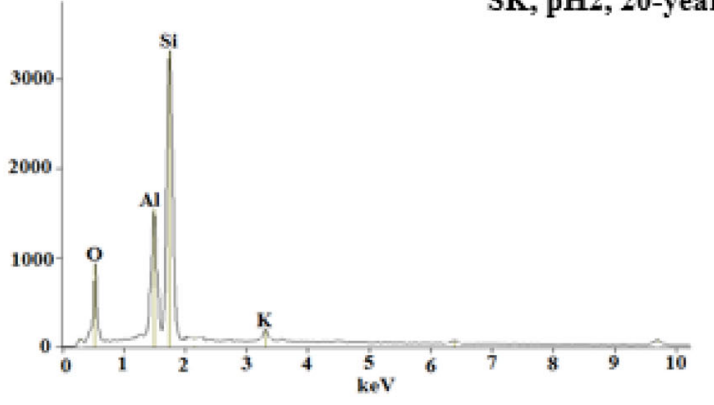

(b)

Fig. 18 SEM and EDX analyses of SK in original conditions and pH 2 in flux of SAR 1 year to 20 years a SEM images, b EDX images

increased the bonding between the finer particles of soils [38-40]. This process destroyed the bonds between clay particles/aggregates: significant changes in mineral structure occurred due to the dissolution of alumina and silica from the PK and SK soils, forming "loose" structures with larger voids. Consequently, the shear strength decreased.

\section{Conclusions}

The results revealed that for both primary kaolinite clay (PK) and secondary kaolinite clay (SK), the low $\mathrm{pH}$ value of simulated acid rain (SAR) and higher flux of SAR resulted in a reduction in soil strength and maximum dry density in compaction tests, and increased compressibility, hydraulic conductivity, liquid limit, and optimum moisture content. The results showed that the effect of acidic environment were higher for PK specimens than those of the SK specimens. The greatest number of intrusion effects was observed when the $\mathrm{pH}$ value was 2 and the flux of SAR was equivalent to precipitation for 20 years. The atomic adsorption spectroscopy (AAS) and energy dispersive X-ray spectroscopy (EDX) results confirmed that most of the traced elements and metallic cations, including $\mathrm{Fe}^{3+}$ and $\mathrm{Al}^{3+}$, were leached out from the soil matrix when the $\mathrm{pH}$ decreased. Also, scanning electron microscope analyses confirmed the formation of a relatively weak structure after acid rain treatment. It was concluded that acid rain led to important changes on ground engineering properties of kaolinite clays.

Acknowledgments The authors sincerely give thanks to the University Putra Malaysia and Fundamental Research Grant Scheme (FRGS/5524133) entitled 'acid rain intrusion effects and slope failure phenomena and mechanisms" for financial support for this research. Moreover, sincere thanks are due to Dr. Hossein Jahangirian from the USA who shared some particularly fruitful discussions with us. 


\section{References}

1. Denman KL, Brasseur G, Chidthaisong A, Ciais P, Cox PM, Dickinson RE, Hauglustaine D, Heinze C, Holland E, Jacob D (2007) Couplings between changes in the climate system and biogeochemistry. Clim Change 2007:541-584

2. Galloway JN (1989) Atmospheric acidification: projections for the future. Ambio 161-166

3. Kato N, Akimoto $\mathrm{H}$ (1992) Anthropogenic emissions of $\mathrm{SO}_{2}$ and $\mathrm{NO}_{\mathrm{x}}$ in Asia: emission inventories. Atmos Environ A 26(16):2997-3017

4. Streets D, Waldhoff S (2000) Present and future emissions of air pollutants in China: $\mathrm{SO}_{2}, \mathrm{NOx}$, and $\mathrm{CO}$. Atmos Environ 34(3):363-374

5. Menon S, Denman KL, Brasseur G, Chidthaisong A, Ciais P, Cox PM, Dickinson RE, Hauglustaine D, Heinze C, Holland E (2007) Couplings between changes in the climate system and biogeochemistry. Ernest Orlando Lawrence Berkeley National Laboratory, Berkeley

6. Santamarina J, Klein K, Wang Y, Prencke E (2002) Specific surface: determination and relevance. Can Geotech J 39(1):233-241

7. Benna M, Kbir-Ariguib N, Clinard C, Bergaya F (2002) Cardhouse microstructure of purified sodium montmorillonite gels evidenced by filtration properties at different $\mathrm{pH}$. Adsorption and Nanostructure. Springer, Berlin, pp 204-210

8. Brandenburg U, Lagaly G (1988) Rheological properties of sodium montmorillonite dispersions. Appl Clay Sci 3(3):263-279

9. Gajo A, Maines M (2007) Mechanical effects of aqueous solutions of inorganic acids and bases on a natural active clay. Géotechnique 57(8):687-699

10. Gori $\mathrm{U}$ (1994) The $\mathrm{pH}$ influence on the index properties of clays. Bull Int Assoc Eng Geol 50(1):37-42

11. Gratchev IB, Sassa K (2009) Cyclic behavior of fine-grained soils at different $\mathrm{pH}$ values. J Geotech Geoenviron Eng 135(2):271-279

12. Jozefaciuk G, Bowanko G (2002) Effect of acid and alkali treatments on surface areas and adsorption energies of selected minerals. Clays Clay Miner 50(6):771-783

13. Sridharan A, El-Shafei A, Miura N (2002) Mechanisms controlling the undrained strength behavior of remolded Ariake marine clays. Mar Georesour Geotechnol 20(1):21-50

14. Sridharan A, Rao S, Murthy N (1988) Liquid limit of kaolinitic soils. Geotechnique 38(2):191-198

15. Ayers G, Peng LC, Fook LS, Kong CW, Gillett R, Manins P (2000) Atmospheric concentrations and deposition of oxidised sulfur and nitrogen species at Petaling Jaya, Malaysia, 1993-1998. Tellus B 52(1):60-73

16. So HB, Lal R (2002) Encyclopedia of soil science. Taylor \& Francis, New York

17. Tan K, Bartlett RJ (1994) Principles of soil Chemistry. Soil Sci 157(5):330

18. Dixon JB, Schulze DG (2002) Soil mineralogy with environmental applications. Soil Science Society of America Inc., Madison

19. Bolland MDA, Posner A, Quirk J (1976) Surface charge on kaolinites in aqueous suspension. Soil Res 14(2):197-216
20. Evans GO (1992) Principles of acarology, vol 18. CAB International, Wallingford

21. Bloodworth A, Highley DE, Mitchell C (1993) Industrial minerals laboratory manual: Kaolin

22. Scorzelli G, Paoluzzi A, Pascucci V (2008) Parallel solid modeling using BSP dataflow. Int J Comput Geom Appl 18(05):441-467

23. Tan KH (2010) Principles of soil chemistry. CRC Press, Boca Raton

24. Norton R (1985) Aspects of the biology and systematics of soil arachnids, particularly saprophagous and mycophagous mites. Quaest Entomol 21:523-541

25. Shamshuddin J, Anda M (2008) Charge properties of soils in Malaysia dominated by kaolinite, gibbsite, goethite and hematite. Bull Geol Soc Malays 54:27-31

26. Scorzelli R, Bertolino L, Luz A, Duttine M, Silva F, Munayco P (2008) Spectroscopic studies of kaolin from different Brazilian regions. Clay Miner 43(1):129-135

27. BS1377-7 BS- (2003) Code of practice for soil engineering purposes: Shear strength tests (total stress). British Standards Institution, Milton, UK

28. Sridharan A, Sivapullaiah PV (2005) Mini compaction test apparatus for fine grained soils. Geotech Test J 28(3):1-7

29. Assaad JJ, Harb J (2012) Use of the falling-head method to assess permeability of freshly mixed cementitious-based materials. J Mater Civ Eng 25(5):580-588

30. Chorom M, Rengasamy P (1995) Dispersion and zeta potential of pure clays as related to net particle charge under varying $\mathrm{pH}$, electrolyte concentration and cation type. Eur J Soil Sci 46(4):657-665

31. Jones JB Jr (2001) Laboratory guide for conducting soil tests and plant analysis. CRC Press, Boca Raton

32. Heil D, Sposito G (1993) Organic matter role in illitic soil colloids flocculation: II. Surface charge. Soil Sci Soc Am J 57(5):1246-1253

33. Lorenz PB (1969) Surface conductance and electrokinetic properties of kaolinite beds. Clays Clay Miner 17(4):223-231

34. Stevenson FJ (1994) Humus chemistry: genesis, composition, reactions. Wiley, New York

35. Van Olphen H, Hsu PH (1978) An Introduction to Clay Colloid Chemistry. Soil Sci 126(1):59

36. Sridharan A, Rao GV (1973) Mechanisms controlling volume change of saturated clays and the role of the effective stress concept. Geotechnique 23(3):359-382

37. Kamon M, Ying C, Katsumi T (1997) Effect of acid rain on physico-chemical and engineering properties of soils. Soils Found 37(4):23-32

38. Bell FG (2013) Fundamentals of engineering geology. Elsevier, Amsterdam

39. Moh Z-C, Mazhar MF (1900) Effects of method of preparation on index properties of lateritic soils. Paper presented at the Soil Mech \& Fdn Eng Conf Proc/Mexico

40. Ola S (1978) Geotechnical properties and behaviour of some stabilized Nigerian lateritic soils. Q J Eng GeolHydrogeol 11(2):145-160 